Prepared for the U.S. Department of Energy

under Contract DE-AC05-76RL01830

\title{
Modeling Activities in the Department of Energy's Atmospheric Sciences Program
}

\author{
JD Fast \\ SJ Ghan \\ SE Schwartz
}

March 2009

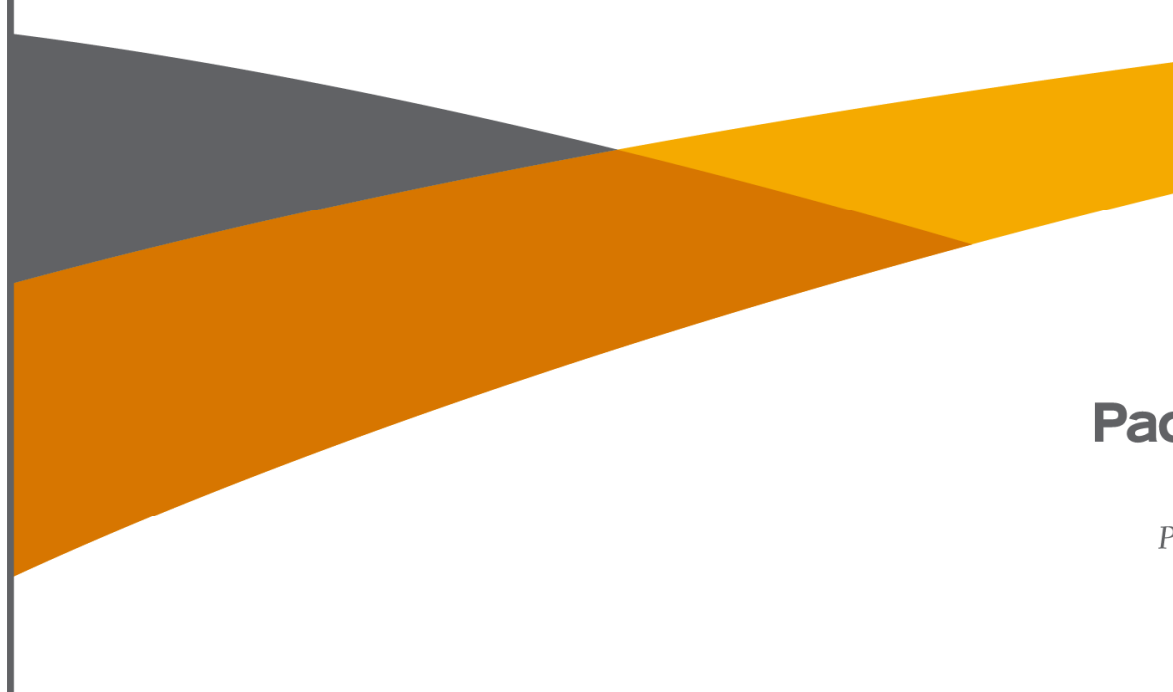




\section{Modeling Activities in the Department of Energy's Atmospheric Sciences Program}

JD Fast - Pacific Northwest National Laboratory

SJ Ghan - Pacific Northwest National Laboratory

SE Schwartz - Brookhaven National Laboratory

March 2009

Prepared for

the U.S. Department of Energy

under Contract DE-AC05-76RL01830

Pacific Northwest National Laboratory

Richland, Washington 99352 


\section{Executive Summary}

The Department of Energy's Atmospheric Science Program (ASP) conducts research pertinent to radiative forcing of climate change by atmospheric aerosols. The program consists of approximately 40 highly interactive peer-reviewed research projects that examine aerosol properties and processes and the evolution of aerosols in the atmosphere. Principal components of the program are instrument development, laboratory experiments, field studies, theoretical investigations, and modeling. The objectives of the Program are to 1) improve the understanding of aerosol processes associated with light scattering and absorption properties and interactions with clouds that affect Earth's radiative balance and to 2) develop model-based representations of these processes that enable the effects of aerosols on Earth's climate system to be represented properly in global-scale numerical climate models. Although only a few of the research projects within ASP are explicitly identified as primarily modeling activities, modeling actually comprises a substantial component of a large fraction of ASP research projects. This document describes the modeling activities within the Program as a whole, the objectives and intended outcomes of these activities, and the linkages among the several modeling components and with global-scale modeling activities conducted under the support of the Department of Energy's Climate Sciences Program and other aerosol and climate research programs. 


\section{Acronyms and Abbreviations}

ASP

ARM

BNL

CalTech

CAM

CARES

$\mathrm{CCN}$

CCPP

CCSM

CCSP

CHAPS

CMAQ

CTM

$\mathrm{CSU}$

$\mathrm{CU}$

DOE

E-AIM

EnKF

ECPP

GCM

GChM-O

GISS

HSRL

IMPACT

IN

ISDAC

LaRC

LBNL

LLNL
DOE's Atmospheric Sciences Program

DOE's Atmospheric Radiation Measurement Program

Brookhaven National Laboratory

California Institute of Technology

Community Atmospheric Model

Carbonaceous Aerosol and Radiative Effects Study

cloud condensation nuclei

Climate Change Prediction Program

Community Climate System Model

U.S. Climate Change Science Program

Cumulus Humilis Aerosol Processing Study

Community Model for Air Quality

chemical transport model

Colorado State University

University of Colorado

U.S. Department of Energy

Extended AIM aerosol thermodynamics model

ensemble adjustment Kalman filter

Explicit-Cloud Parameterized-Pollutant

global climate model

Global Chemistry Model driven by observed meteorology

NASA Goddard Institute for Space Studies

high resolution spectral lidar

Integrated Massively Parallel Atmospheric Chemistry Transport model

ice nuclei

Indirect and Semi-Direct Aerosol Campaign

Langley Research Center

Lawrence Berkeley National Laboratory

Lawrence Livermore National Laboratory 
MASE

MADRID

MILAGRO

MIRAGE

MM5

MMF

MOSAIC

NASA

NCAR

NCSU

NOAA

NSF

PNNL

POA

QMOM

RegCM

SciDAC

SGMM

SOA

UALR

UC-Davis

UC-Irvine

UC-Riverside

UM

VOC

VOCALS-Rex

WRF

WRF-Chem
MArine Stratus Experiment

Model of Aerosol Dynamics, Reaction, Ionization and Dissolution

Megacity Initiative: Local and Global Research Observations

Model for Integrated Research on Atmospheric Global Exchanges

Mesoscale Meteorology model version 5

Multiscale Modeling Framework

MOdel for Simulating Aerosol Interactions and Chemistry

National Aeronautics and Space Administration

National Center for Atmospheric Research

North Carolina State University

National Oceanic and Atmospheric Administration

National Science Foundation

Pacific Northwest National Laboratory

primary organic aerosol

Quadrature Method of Moments model

Regional Climate Model

DOE's Scientific Discovery through Advanced Computing

self-generating master mechanism

secondary organic aerosol

University of Arkansas - Little Rock

University of California - Davis

University of California - Irvine

University of California - Riverside

University of Minnesota

volatile organic compound

Variability of the American Monsoon System (VAMOS) Ocean-Cloud-AtmosphereLand Study Regional Experiment

Weather Research and Forecasting model

chemistry version of the Weather Research and Forecasting model 


\section{Contents}

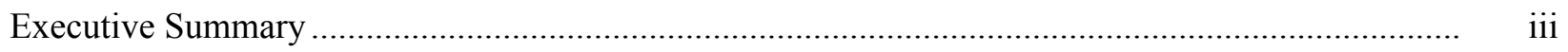

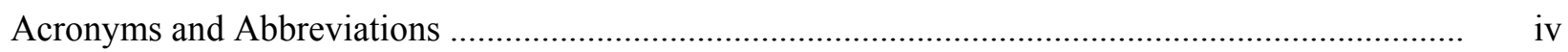

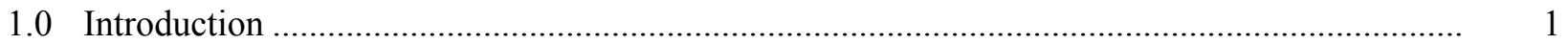

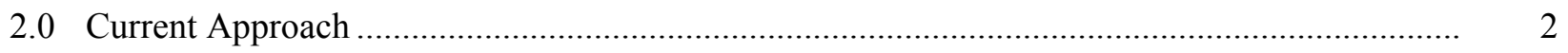

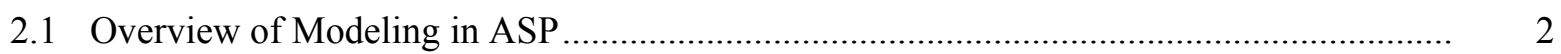

2.2 Modeling in ASP in Relation to other DOE Programs.........................................................

2.3 Current Modeling Activities...................................................................................... 4

2.4 Linkages Among ASP Modeling Activities ................................................................... 8

2.5 Linkages to Other Modeling Activities ................................................................................ 9

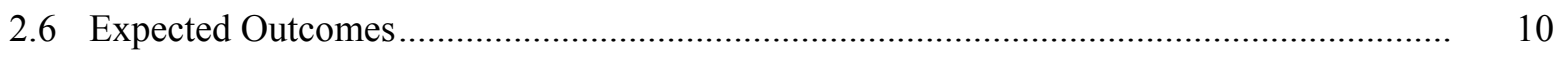

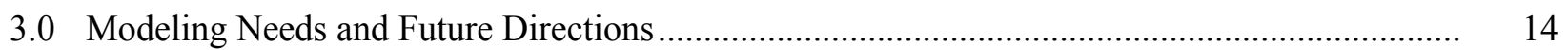

3.1 Accelerating the Use of Advanced Aerosol Property and Process Models......................... 14

3.2 Improving Linkages Among ASP Activities................................................................. 15

3.3 Establishing Aerosol Modeling Testbeds........................................................................ 15

3.4 More Extensive Simulations to Better Examine Parameter Space ..................................... 17

3.5 Global Climate Model Link: Direct Testing …........................................................... 18

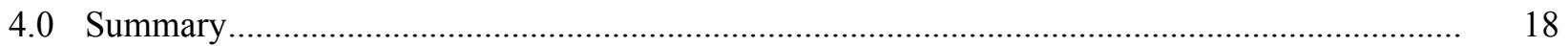

Appendix A - Summary of ASP Modeling Projects .................................................................. A.1

Appendix B - Specific Collaborative Activities Among ASP Modeling Projects ............................. B.1 


\section{Figures}

1 Relationship of ASP Research Components Associated with Different Modeling Approaches .. 2

2 Relationship Between the Components of ASP Research and Research Elements in the

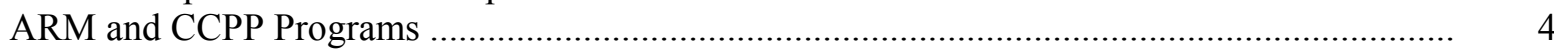

3 Modeling Projects Currently Supported by ASP and Linkages Among the Projects .................. 9

4 Relationship of Future Aerosol Modeling Testbed Future Activities, in Relation to the Fundamental Approaches Employed by ASP.....

\section{Tables}

1 Modeling Activities in the Current ASP Research Portfolio 


\subsection{Introduction}

The focus of research performed by the Department of Energy's Atmospheric Sciences Program (ASP) is improving the understanding of 1) atmospheric processes governing the formation, transformation, and removal of atmospheric aerosols (suspended solid or liquid particulate matter) associated with energy-related and other emissions and 2) the properties of these aerosols pertinent to radiative forcing of climate change. The reconfiguration of ASP since 2004 was brought about in recognition of the substantial contribution of anthropogenic aerosols to radiative forcing of climate change over the industrial period and of the large uncertainty in present estimates of this forcing.

As described in some detail by Ghan and Schwartz, ${ }^{1}$ the approach employed by ASP to develop the required understanding of atmospheric processes that govern aerosol evolution and aerosol radiative forcing needed by the climate modeling community consists of following broad categories of research activities:

Instrumentation development that provides improved methodologies for measuring the amounts and properties of atmospheric aerosols and other quantities that affect aerosols for both field measurements and laboratory experiments.

Laboratory experiments that determine the dependence of controlling variables and concentration of trace gases and particles or relate optical and cloud nucleating properties of aerosols to sizedependent composition under controlled conditions.

Field measurements that quantify properties of particulate matter in the atmosphere, identify important transformation processes, and permit the evaluation aerosol processes represented in models.

Theory that provides a framework for interpreting laboratory and field experiment results and their extension beyond the conditions measured.

Modeling that develops and evaluates numerical treatments of aerosol processes on a variety of spatial scales, from 0-D (i.e., box model) to local, regional, and global three-dimensional representations.

Research in ASP is conducted by a highly interactive portfolio of peer-reviewed research projects conducted by investigators at DOE National Laboratories, other Federal Laboratories, universities, and the private sector. ASP is located organizationally within DOE's Climate and Environmental Science Division and interacts with other programs in that division, including the Atmospheric Radiation Measurement (ARM) Program and the Climate Change Prediction Program (CCPP). More broadly, ASP interacts with other research activities on atmospheric composition and radiative forcing carried out under the auspices of the U.S. Climate Change Science Program (CCSP) and similar international research endeavors.

\footnotetext{
${ }^{1}$ Ghan SJ, and SE Schwartz. 2007. "Aerosol Properties and Processes: A Path from Field and Laboratory Measurements to Global Climate Models." Bulletin of the American Meteorological Society 88(7):1059-1083. doi:10.1175/BAMS-88-7-1059
} 
This document describes ongoing modeling activities in ASP, shows the connections of these activities to each other and to other activities in the broader climate change research community, and identifies products and deliverables of ASP research. Gaps in the current portfolio of ASP modeling activities are identified and means of filling these gaps also are addressed.

\subsection{Current Approach}

\subsection{Overview of Modeling in ASP}

A fundamental premise of the approach employed by ASP is that a quantitative description of important atmospheric processes that affect aerosols must be represented accurately in climate models. Many of these processes, such as chemical reactions, condensation, and coagulation are inherently local. But these local processes are coupled with larger-scale meteorological processes, such as transport and mixing, cloud-aerosol interactions, and wet and dry deposition that affect the concentration, composition, and size distribution of atmospheric particles. The interactions of local and larger-scale processes are often non-linear and complex. Representing aerosol processes in climate models necessitates development and evaluation of models suitable for application at a variety of scales: local (0-D) property and process models, regional-scale models, and global-scale models. The numerical representations of aerosol processes are often highly parameterized because of computational constraints, especially so for global-scale climate models. The overall multi-scale approach of modeling and the relationship between ASP laboratory, field, and modeling activities is outlined in Figure 1.

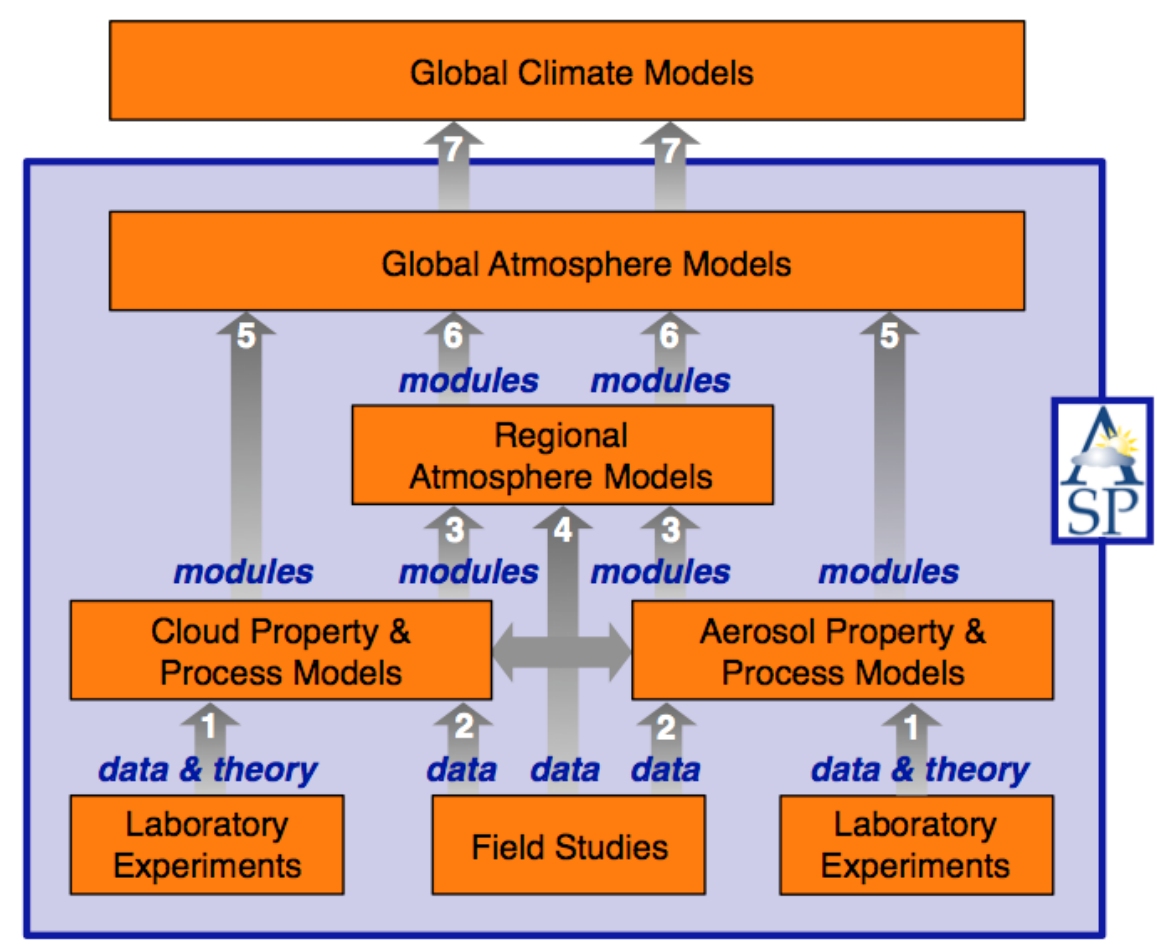

Figure 1. Relationship of ASP Research Components Associated with Different Modeling Approaches 
The product of a laboratory experiment is a new or improved theoretical representation of a specific property or process, generally in zero dimensions. In some instances such representations can be immediately incorporated into global models, but usually they first need to be incorporated into more complex 0-D models that take into account multiple aerosol properties and processes (arrow 1, Figure 1). In this way, the behavior of a new or improved theoretical representation can be assessed when it interacts with representations of other particle processes and the performance can be quantified using measurements made during field studies (arrow 2, Figure 1).

In contrast with 0 -D aerosol property and process models that assume uniform conditions within a volume element (i.e., 'box') of the atmosphere, the domains of three-dimensional models encompass substantial gradients in aerosol concentrations, aerosol transformation rates, and meteorological conditions that influence these concentrations and rates. Three-dimensional models are required to simulate the full life cycle of the aerosol, coupling particulate transformation processes that occur in individual grid cells with a description of the transport and mixing between grid cells, emissions of primary particles and precursor gases, atmospheric radiation, cloud processing, and removal of particles and precursor gases by wet and dry deposition. Grid cells employed by large-scale models, however, do not generally resolve gradients in aerosol properties that are commonly observed. Consequently, many atmospheric processes pertinent to aerosols must be dealt with by employing parameterizations. But these parameterizations also introduce uncertainties into models.

In general, there are three types of three-dimensional atmospheric models: large-eddy simulation, regional, and global. Large-eddy simulation models employ grid spacings of $10-100 \mathrm{~m}$ so that local atmospheric processes can be resolved, such as the interaction of aerosols and cloud microphysics and the chemical transformation of aerosols within boundary layer eddies. Regional models, which employ horizontal grid spacings of $1-50 \mathrm{~km}$, resolve much of the spatial and temporal variability in concentrations and properties of aerosols and aerosol precursors commonly observed in field studies. These models also are able to include quite explicit representations of aerosol processes because of the limited domains and time periods for which such models are commonly applied. Therefore, it is desirable to test modules obtained from 0 -D aerosol property and process models within regional models (arrow 3 , Figure 1) to evaluate their performance by comparison with field study measurements (arrow 4, Figure 1). Global models employ relatively coarse horizontal grid spacings (e.g., $50-100 \mathrm{~km}$ ) and simplified treatments of aerosol processes to limit the computational expense associated with simulating atmospheric conditions over long time scales (decades to centuries). After aerosol property and process models have been tested and evaluated, they can provide modules that can be incorporated into global models (arrow 5 , Figure 1).

It is usually difficult to assess the performance of new aerosol process modules within global models because their coarse grid spacing does not resolve the large spatial variations in particles, aerosol radiative forcing, and meteorological conditions often observed in the atmosphere. After the modules have been tested and evaluated against field data to assess their performance, they can be incorporated into global models with much greater confidence (arrow 6, Figure 1). In addition to an improved basic understanding of aerosol properties, the primary purpose of ASP modules is their contribution to global scale climate models (arrow 7, Figure 1). 


\subsection{Modeling in ASP in Relation to other DOE Programs}

As noted in the previous section, ASP conducts laboratory experiments, field studies, aerosol property and process modeling, and three-dimensional modeling on regional and global scales to improve the understanding of aerosol evolution. The ARM program employs a similar approach, except that the focus is on cloud properties and radiative effects of clouds. Because aerosols influence atmospheric radiation and clouds and likewise clouds and radiation have a profound effect on aerosol properties, there is some overlap between the two programs. Many of the aerosol and cloud process modules developed by the ASP and ARM programs are used by global climate models studies in the CCPP program. The relationship between ASP modeling activities to other related activities in the ARM and CCPP programs is depicted in Figure 2.

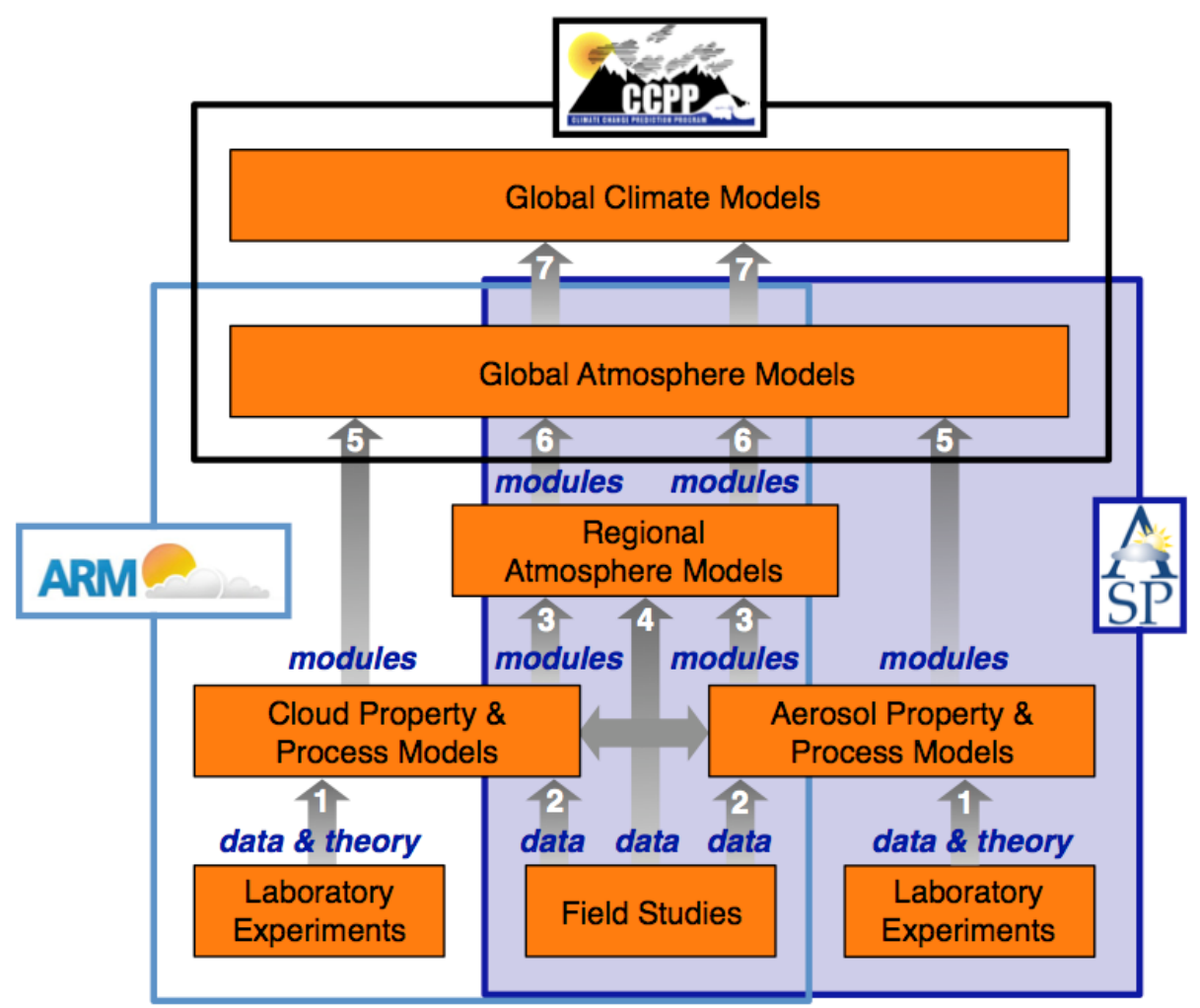

Figure 2. Relationship Between the Components of ASP Research and Research Elements in the ARM and CCPP Programs

\subsection{Current Modeling Activities}

Modeling is the sole focus or a major component of many ASP research projects. These projects are listed in Table 1 grouped according to the approaches depicted in Figure 1. A more detailed description of these activities is included in the Appendix A. 
Table 1. Modeling Activities in the Current ASP Research Portfolio. Note: The list does not contain all of the investigators making significant contributing to these activities, including the collaborations among ASP investigators.

Aerosol Property and Process Modeling Activities:

\begin{tabular}{|c|c|c|}
\hline Principal Investigator & Institution & Description \\
\hline Barnard & PNNL & Optical properties of aerosols and optical property closure \\
\hline Finlayson-Pitts & UC - Irvine & $\begin{array}{l}\text { Formation of secondary organic aerosols via nitrate ion photochemistry } \\
\text { based on laboratory experiments }\end{array}$ \\
\hline Gaffney & UALR & $\begin{array}{l}\text { Residence times of size-fractionated fine aerosols via relative amounts } \\
\text { of attached natural radionuclides }\end{array}$ \\
\hline Gilles \& Laskin & $\begin{array}{l}\text { LBNL \& } \\
\text { PNNL }\end{array}$ & $\begin{array}{l}\text { Speciation of organic functional groups with age and characterization of } \\
\text { particle black carbon mixing states and biomass burning particles }\end{array}$ \\
\hline Hostetler \& Ferrare & NASA LaRC & $\begin{array}{l}\text { Aerosol distributions and properties from lidar remote sensing field } \\
\text { measurements to be used for transport model evaluation }\end{array}$ \\
\hline Martin & Harvard & $\begin{array}{l}\text { Reactive chemistry and changing } \mathrm{CCN} \text { properties of secondary organic } \\
\text { aerosols based on laboratory experiments }\end{array}$ \\
\hline Madronich & NCAR & $\begin{array}{l}\text { Atmospheric oxidation of organic compounds and their gas-particle } \\
\text { partitioning using explicit modeling techniques }\end{array}$ \\
\hline Marley & UALR & $\begin{array}{l}\text { Aerosol absorption and scattering efficiencies, optical constants, and } \\
\text { Angstrom exponents based on field measurements }\end{array}$ \\
\hline McGraw & BNL & Modeling the deliquescence and efflorescence of small particles \\
\hline McGraw & BNL & Modeling the nucleation and growth of terrestrial biogenic aerosols \\
\hline McMurry & $\begin{array}{l}\mathrm{UM} \& \\
\text { NCAR }\end{array}$ & $\begin{array}{l}\text { Reconciling measured and modeled growth rates of atmospheric } \\
\text { nanoparticles based on field and laboratory studies }\end{array}$ \\
\hline Schwartz & BNL & Relative humidity dependence of aerosol size and optical properties \\
\hline Seinfeld & CalTech & Process models that predict the formation of secondary organic aerosol \\
\hline Wexler \& Clegg & UC - Davis & $\begin{array}{l}\text { A thermodynamic process model that includes the equilibrium size and } \\
\text { state of aerosols containing both organic and inorganic components. }\end{array}$ \\
\hline Zaveri & PNNL & $\begin{array}{l}\text { New treatments for primary and secondary organic aerosols and black } \\
\text { carbon aging using laboratory data and benchmark models }\end{array}$ \\
\hline $\begin{array}{l}\text { Ziemann \& } \\
\text { Kreidenweis/Petters }\end{array}$ & $\begin{array}{l}\text { UC Riverside } \\
\& \text { CSU }\end{array}$ & $\begin{array}{l}\text { Hygroscopicity and CCN activity of SOA and processed POA and their } \\
\text { relationships to chemical composition based on laboratory studies }\end{array}$ \\
\hline
\end{tabular}


$\underline{\text { Cloud Property and Process Modeling Activities: }}$

\begin{tabular}{lll}
\hline \multicolumn{1}{c}{ Principal Investigator } & Institution & \multicolumn{1}{c}{ Description } \\
\hline Ervens \& Feingold & CU / NOAA & Chemical mechanisms associated with organic aerosols in clouds \\
Laskin \& Gilles/Moffet & $\begin{array}{l}\text { LBNL \& } \\
\text { PNNL } \\
\text { Ovtchinnikov \& Easter }\end{array}$ & $\begin{array}{l}\text { Closure of CCN, sulfur partitioning in the marine boundary layer, and } \\
\text { compositional effects on CCN/IN ability in field measurements } \\
\text { Perosol processing within clouds and parameterized treatments based on } \\
\text { cloud-resolving modeling } \\
\text { Aerosol cloud condensation nuclei spectrum, cloud droplet activation, } \\
\text { and droplet growth kinetics based on closure studies }\end{array}$ \\
\hline
\end{tabular}

$\underline{\text { Regional Modeling Activities: }}$

\begin{tabular}{|c|c|c|}
\hline Principal Investigator & Institution & Description \\
\hline Berg & PNNL & Representation of cloud-aerosol interactions in regional models \\
\hline Fast & PNNL & $\begin{array}{l}\text { Evaluating predictions of particulate properties associated with field } \\
\text { study measurements using current and new aerosol process modules }\end{array}$ \\
\hline Gustafson \& Ghan & PNNL & $\begin{array}{l}\text { Parameterization for global models that treats sub-grid scale vertical } \\
\text { transport, processing, and scavenging of particles by clouds }\end{array}$ \\
\hline Kotamarthi & ANL & Methods of quantifying model uncertainty \\
\hline Qian \& Gustafson & PNNL & $\begin{array}{l}\text { Quantify sources of sub-grid scale aerosol variability and treatments to } \\
\text { represent those processes in larger-scale models }\end{array}$ \\
\hline Schwartz & BNL & $\begin{array}{l}\text { Examine the sensitivity of aerosol properties and distributions to } \\
\text { nucleation and emissions }\end{array}$ \\
\hline Wang & BNL & $\begin{array}{l}\text { Cloud droplet activation of organic aerosols and the effects of sub-grid } \\
\text { variations of aerosol properties on cloud formation }\end{array}$ \\
\hline
\end{tabular}

Global Modeling Activities:

\begin{tabular}{|c|c|c|}
\hline Principal Investigator & Institution & Description \\
\hline Chuang & LLNL & $\begin{array}{l}\text { Global modeling and validation of formation, transformation, and } \\
\text { radiative forcing of secondary organic aerosols }\end{array}$ \\
\hline Schwartz & BNL & Inverse modeling of global aerosol forcing \\
\hline $\begin{array}{l}\text { Meskhidze, Zhang, \& } \\
\text { Kamykowski }\end{array}$ & $\mathrm{NCSU}$ & $\begin{array}{l}\text { SOA treatments and quantifying the effect of terrestrial and marine } \\
\text { organic aerosols in global models }\end{array}$ \\
\hline
\end{tabular}

The modeling activities listed in Table 1 contain one or more of the following types of research: model development, forecasting, evaluation studies, closure studies, and insight studies.

Model development: There is a continuing need to develop models because they must incorporate the latest findings on aerosol processes and new approaches for representing these processes numerically. Some modifications to existing models are relatively straightforward, such as adding or modifying a reaction rate. Other modifications can be complex, such as implementing treatments of secondary organic aerosols (SOA) that involves many trace gas and particle species and their interactions as well as coupling the new components to emissions, transport, cloud-aerosol interactions, and deposition. Model development also includes developing totally new models based on conceptual relationships that would 
not work in existing models. These new models often contain very complex treatments that are computationally expensive (e.g., large-eddy simulation models, cloud-resolving models, particle-resolved models) that cannot be used for long-term real world conditions. However, they provide new insights into aerosol processes that can then be used to develop parameterized treatments for existing aerosol property, regional, and global models.

Forecasting: Models are essential tools to assist in planning and conducting field experiments. They can be run with relatively little expense to examine transport pathways of aerosols, quantify the frequency of a particular parameter at a specific site given the time varying ambient meteorological conditions, and help formulate the scientific questions regarding model performance of specific aerosol processes that will be measured. In this way, investigators have specific information on what to expect before deploying instrumentation in the field and can adjust measurement strategies accordingly. Pre-field campaign modeling studies have been conducted to great advantage in planning previous ASP field campaigns. After field campaigns, archived forecasts also have been used to help interpret spatial and temporal variations in measured quantities.

Evaluation Studies: Evaluation studies assess the ability of models to simulate the evolution of aerosol properties observed in the atmosphere. For aerosol property and process models, models are run to assess their ability to simulate measurements made during laboratory experiments or during field campaigns at specific locations and times (e.g., Lagrangian trajectory modeling). Regional models are run to assess their ability to simulate aerosol evolution as inferred from data obtained from a wide range of instrumentation during a field campaign conducted over a few days to weeks. Global models are evaluated using data collected from long-term measurements, such as operational surface monitors and satellite retrievals, that have been averaged in time or space to obtain information more compatible with the coarse model resolution. For all types of models, some of the inputs (i.e., initial and boundary conditions) may not be known at all or with high certainty. In many instances, models can be used to assess the consequences of uncertainties in model inputs and to ascertain the extent to which departures between model results and measurements are consistent with uncertainties in model inputs.

Quantification of model performance also must consider the amount of available data, as measurements are inevitably sparse in space and time and current state-of-the-science instrumentation does supply information on many of the lesser-known particulate species and precursor trace gases.

Closure Studies: Closure studies are similar to model evaluation studies except that they employ observations to constrain a portion of the model and they usually focus on a specific aerosol process. The principle of a closure experiment is that the input variables required by the model are determined from measurements. Then the model is run to calculate various aerosol properties that have been determined by a set of independent measurements. If the calculations agree with the observations within their mutual uncertainties, then it can be inferred that the processes are represented in the model. Such closure experiments can take place on a variety of scales from local (e.g., dependence of optical properties on relative humidity, using measured size dependent composition as input) to regional (comparison of measured and modeled evolution of aerosol intensive or extensive properties). The extent to which models are constrained depends on the available observations and other inputs. Data assimilation techniques (e.g., variational methods) can be used to constrain regional models. However, regional models tend to be less constrained than zero dimensional (0-D) models because of uncertainties associated with inputs such as boundary conditions and emissions. 
Insight Studies: After the representations of aerosol process modules have been exercised by either evaluation or closure studies, models can be used to address a wide range of scientific questions that cannot be answered by observations alone. Aerosol process and property models often contain more variables than can be measured currently in the atmosphere. Therefore, the influences of other less well understood trace gas and particles species on the overall aerosol evolution can be assessed. Regional and global models can fill in the gaps of how aerosols evolve in the atmosphere that cannot be achieved logistically and practically with field campaigns. In addition to interpreting the evolution of aerosols in the atmosphere, models can be used to test hypotheses on the impacts of specific atmospheric processes on the evolution of aerosol intensive and extensive properties. As models often contain variables that are not measured currently, they can provide information as to what types of properties need to be characterized by the next generation of instrumentation.

Model development and the various types of numerical studies are necessary to address the following questions relevant to representing aerosols in climate models:

- Which aerosol processes are represented well in models? Which aerosol processes are poorly represented?

- Which aerosol processes lead to large uncertainties in the magnitude and distribution of aerosol radiative forcing?

- What is the best way to represent fundamental mechanisms associated with new particle formation and aerosol transformation processes in models?

- Do new treatments of aerosol processes consistently improve the predictions of aerosols for the right reasons when compared with both laboratory experiments and field experiments?

- What is the most appropriate balance between complexity of aerosol processes and computational efficiency in terms of global modeling?

\subsection{Linkages Among ASP Modeling Activities}

Many of the outcomes from the modeling projects require collaborative research that transfers findings from one project to another in the form of aerosol process modules. The current individual ASP modeling projects are depicted in Figure 3 in terms of the type of their primary approach: Aerosol Process \& Property, Cloud Process \& Property, Regional, and Global Modeling. Because of the small spatial scales employed by large-eddy simulation models, they are included in the Cloud Process \& Property approach. While some of the listed projects are primarily laboratory or field studies, they provide key information needed to develop and test new aerosol processes in 0-D model representations.

Figure 3 shows several pathways where laboratory measurements are used to develop new theoretical relationships for aerosol process modules. These new process modules are subsequently integrated into regional and global models and evaluated with field measurements. In general, most of these collaborative research activities are focused on SOA, cloud-aerosol interactions, or aerosol optical properties. A detailed description of collaborative research activities among the projects is described in Appendix B. 


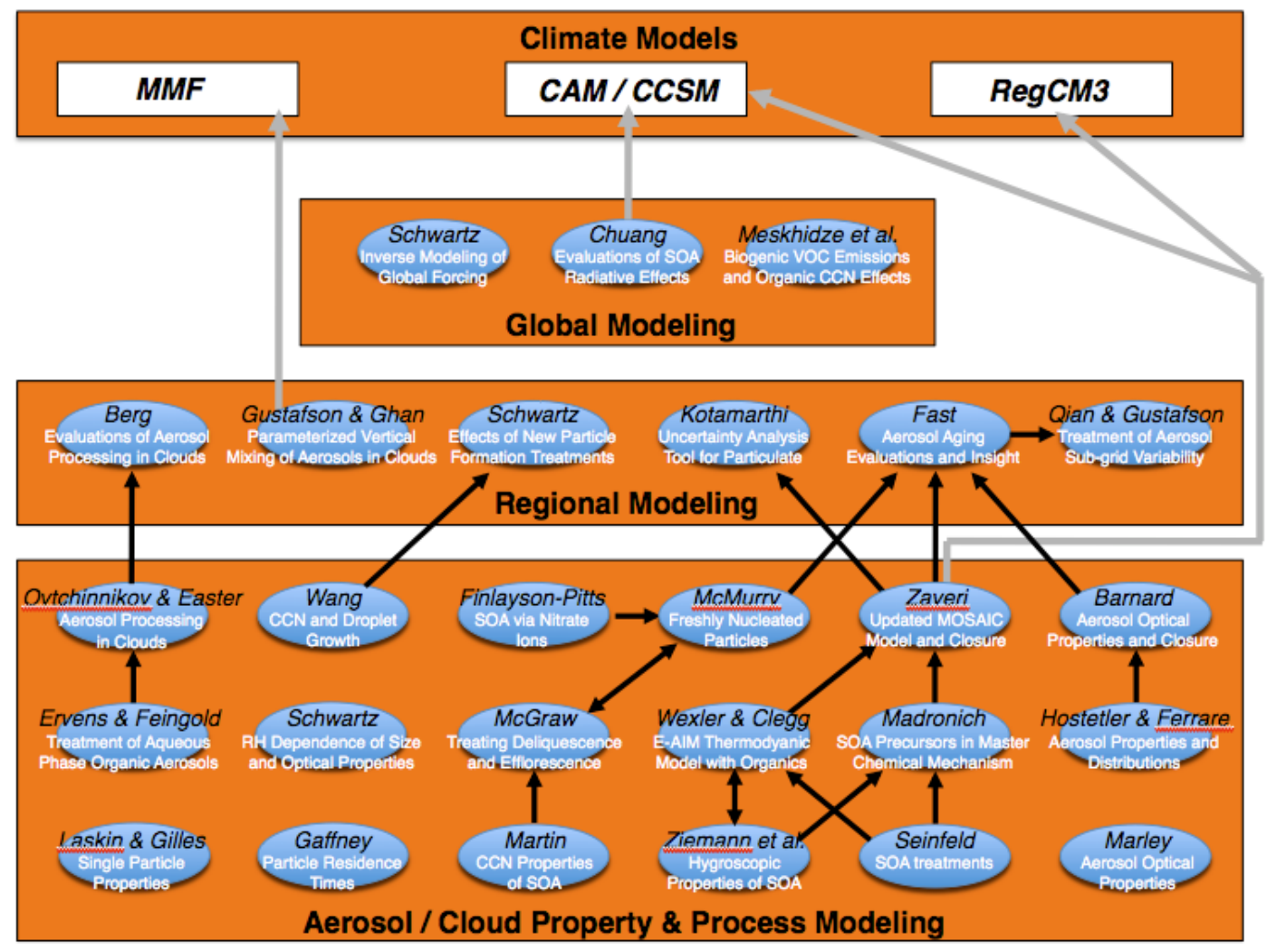

Figure 3. Modeling Projects Currently Supported by ASP and Linkages Among the Projects

\subsection{Linkages to Other Modeling Activities}

Linkages of ASP modeling projects to activities supported by other agencies include:

- The parameterized treatments of the vertical mixing and chemistry of aerosols in explicit clouds has been developed using the regional WRF model in Gustafson and Ghan's project. The resulting Explicit-Cloud Parameterized-Pollutant (ECPP) module will be implemented in the CAM-based MMF global model, under NASA support, since this model has a component that resolves clouds at relatively high resolution.

- Nucleation (particle production) rates observed in the atmosphere are typically orders of magnitude higher than are predicted by theories. In 2005, McMurry and NCAR scientists were funded by NSF to investigate processes responsible for these high nucleation rates. Again, this research involves an integrated program of instrument development, field observations, and laboratory research. We have developed a cluster chemical ionization mass spectrometer (Cluster CIMS) for measuring the masses and concentrations of neutral molecular clusters formed by nucleation as well as new aerosol instruments capable of measuring size distributions of particles as small as $1 \mathrm{~nm}$. We are using these instruments to carry out atmospheric and laboratory studies. Using our existing database for measurements carried out around the globe we have empirically found that nucleation rates, J, can be expressed as $\mathrm{J}=\mathrm{K}\left[\mathrm{H}_{2} \mathrm{SO}_{4}\right]^{2}$, where the prefactor, $\mathrm{K}$, varies from location-to-location. Our current work focuses on understanding factors that determine variability in $\mathrm{K}$ and reasons for the squared dependence on $\left[\mathrm{H}_{2} \mathrm{SO}_{4}\right]$. 
- Laskin, Gilles, and Moffet participated in the Indirect and Semi-Direct Aerosol Campaign (ISDAC) field campaign led by the ARM program. During ISDAC Laskin, Gilles, and Moffet flew a dualcolumn CCN counter operating at two different supersaturations as well as a sampler for SEM and STXM microscope measurements. These measurements alternated between ambient aerosol and cloud droplet/crystal residuals so that $\mathrm{CCN}$ closure and composition compositional measurements could be carried out in collaboration with S. Brooks (ARM / Environment Canada).

- A moment-based representation of new particle formation rates, developed by McGraw, has been implemented in the NASA Goddard Institute for Space Studies global climate model to examine the accuracy and feasibility of this approach.

- Other major elements of Wexler and Clegg's project, which are supported by other agencies (NOAA and the U.K. Met Office), include the addition of further inorganic species to the model (e.g., soluble components of windblown dust), model revisions relevant to upper tropospheric aerosols, and the addition of size (Kelvin) effects.

- The prediction of size-resolved aerosol concentrations and compositions in Chuang's project is closely linked to our DOE ARM project to examine the aerosol indirect effects and enhance the predictability of aerosol impacts on climate. After adequate validation with observations, the SOA chemistry mechanism and LLNL version's MADRID will be implemented into CAM3 to improve the existing treatment of gas to particle conversion as part of a DOE SciDAC project.

- Versions of Zaveri's MOSAIC model are being implemented in both the CAM and RegCM climate models under SciDAC and NSF support, respectively.

\subsection{Expected Outcomes}

The following are the new aerosol process modules that we expect to be developed and model assessments expected to be performed as part of ASP over the next three years.

- Aerosol Property and Process Modeling Activities

- Extended Aerosol Inorganics Model (E-AIM): A thermodynamic model is being extended to include a treatment for secondary organic aerosols to serve as a benchmark for developing thermodynamic tools suitable for regional and global models. The reference model will include the major inorganic ions, a flexible framework for including organic aerosol species or lumped components, and a parameterized SOA treatment based on results from concurrent ASP projects (see below). The model includes a web interface (http://www.aim.env.uea.ac.uk/aim/aim.php/) and can be used interactively for many problems [Clegg \& Wexler].

- New Mechanism of SOA Formation/Loss: Potential new mechanisms of SOA formation (and perhaps loss) in the atmosphere are being quantified, parameterized for introduction into regional and global models, and used to assess the results of field measurements of particle composition [FinlaysonPitts].

- Carbonaceous Aerosol Aging and Speciation: The transformation of total carbon, carbon-carbon double bonds, and carbonyl bonds with time is being quantified. Qualitative identification of organic classes from empirical formulas is provided by mass spectrometry [Gilles \& Laskin]. 
- Single Particle Soot Mixing State: The mixing of soot is being quantified by measuring the size of soot inclusions compared to the total particle size to enable a direct comparison to optical models. The extent of this type of mixing will be examined as a function of aerosol age to place limits on parameters used in optical models [Gilles and Laskin].

- Residence Times and Sources of Tropospheric Aerosols: Estimates of aerosol residence times, aerosol removal via washout (particularly for hydrophobic aerosols from fossil fuel and biogenic sources), and the relative contribution of biogenic and fossil fuel sources on organic aerosols needed for model evaluation are being quantified [Gaffney].

- Characterizing Aerosol Distributions and Optical Properties: Vertical profiles of aerosol extinction and aerosol intensive parameters measured by the airborne high spectral resolution lidar (HSRL) are being used to help evaluate the ability of models to reproduce aerosol extinction and optical thickness profiles as well as to help determine how well models can represent horizontal and vertical variations in aerosol types [Hostetler and Ferrare].

- Extended Master Chemical Mechanism (MCM): A new lumped mechanism for trace gas precursors of secondary organic aerosols suitable for regional and global applications is being developed based on explicit simulations of atmospheric photochemistry of anthropogenic and biogenic organics [Madronich].

- Absorption and Scattering Properties of Aerosols: Data sets for aerosol extinction, estimates of the variability of aerosol Angstrom exponents (particularly for absorption), and comparisons of groundbased and aircraft aerosol optical extinction parameters with total column data obtained from MFRSR are being assembled [Marley].

- Simplified expressions and SOA parameters for modeling CCN spectra: Laboratory results from the Harvard Environmental Chamber are being used to provide parameters of fresh and aged SOA for simplified Köhler expressions that can be incorporated within cloud modules of climate and chemical transport models [Martin].

- Process Model Mixed Organic-Inorganic Mixtures: A more reliable model is being developed for predicting the deliquescence, efflorescence, and water uptake properties of aerosol particles as a function of their chemical composition and size [McGraw, Lewis, Smith, Mifflin, and Martin].

- QMOM: A method-of-moments aerosol module is being developed for simulating the growth rates of freshly nucleated particles [McGraw and Zhang].

- Properties of Nanoparticles: A Thermal Desorption Chemical Ionization Mass Spectrometer (TDCIMS) that measures nanoparticle composition and a thermodynamic model for gas-particle partitioning of ionic liquids consisting of organic acids and bases (modeling) is being developed. Vapor pressure data from laboratory studies is being obtained for aerosols produced from mixtures of various organic acids and bases and the contribution of sulfuric acid and various organic compounds to nanoparticle growth rates is being determined from field studies [McMurry].

- Secondary Organic Aerosol Module: A secondary organic aerosol module, suitable for inclusion in regional and global atmospheric chemical transport models, is being developed [Seinfeld]. 
- Updated MOSAIC Aerosol Module and Performance Evaluations: An updated version of the MOSAIC aerosol process \& property module that includes new treatments for primary and secondary organic aerosols and black carbon aging based on laboratory data and benchmark treatments that has also been evaluated using ASP laboratory and field measurements via 0-D closure studies and 3-D WRF-Chem simulations is being developed [Zaveri].

- Particle-Resolved Aerosol Model (PartMC-MOSAIC): A particle-resolved model that explicitly treats coagulation, chemistry, optical properties, and cloud-activation properties of a population of individual particles of different types is being evaluated to interpret single-particle and size-resolved measurements [Zaveri].

- Simplified SOA Hygroscopicity Model: A module is being developed that provides values of the hygroscopicity parameter, a predictor of aerosol water content and CCN activity, for SOA and processed POA particles based upon parent compound, oxidant, extent of oxidation, and carbon numbers and functional groups of products [Ziemann \& Kreidenweis / Petters].

\section{Cloud Property and Process Modeling Activities}

- Mechanism for Aqueous Phase Organic Aerosols: A treatment for simulating the processing of organic aerosols in clouds is being tested and evaluated using ASP field campaign measurements [Ervens and Feingold].

- Identification of CCN and IN Composition and Sources: For different cloud types, the chemical composition of cloud residuals is being analyzed to determine what aerosol types are most efficient at forming cloud droplets and crystals. Ambient aerosol compositions also are being quantified on a number basis to provide insight into ambient sources during the VOCALS and ISDAC campaign. [Laskin \& Gilles/Moffet].

- $\quad$ Cloud-Resolving Model of Aerosol Processing: Vertical transport and processing of aerosols within cumulus and stratocumulus clouds using a cloud-resolving bin microphysics model is being evaluated using ASP field measurements to identify aerosol processes that need to be incorporated into regional and global models [Ovtchinnikov].

- Cloud Droplet Activation of Aerosol: An efficient representation of aerosol properties, which is constrained by and evaluated using field observations, is being developed to improve the treatment of cloud-activation in large-scale models. The representation will include the effect of sub-grid variation of aerosol properties on cloud formation [Wang].

\section{$\underline{\text { Regional Modeling Activities }}$}

- Explicit-Cloud Parameterized-Pollutant (ECPP) Parameterization: A parameterization has been developed for MMF models that improve the vertical mixing and cloud processing of pollutants within clouds that are not resolved adequately by global climate models [Gustafson and Ghan].

- Assessments of Aerosol Process Modules: State-of-the-science aerosol process and optical property modules are being implemented in the community WRF-chem multi-scale model that are tested and evaluated using ASP field campaign measurements [Fast]. 
- Uncertainty Analysis Tool: A tool is being developed that employs an ensemble Kalman filter (EnKF) approach for assessing uncertainties in particulate predictions obtained from the MM5/CMAQ regional aerosol model. Analyses of parameter uncertainty are being computed using parameter sweep procedures implemented for aerosol process models [Kotamarthi].

- Sub-grid Variability of Aerosol Properties: The importance of local and regional-scale processing of aerosols is being assessed and a parameterization of sub-grid scale variability is being developed for improving aerosol-climate impacts in global scale models [Qian \& Gustafson].

\section{Global Modeling Activities}

- Tropospheric Chemistry Mechanisms for Global Applications: A new chemical mechanism is being developed and implemented to the IMPACT model that accounts for SOA, enhances capabilities to precisely link precursor gases (e.g., volatile organic carbon) to aerosol formation and size distribution, and improves predictions of global aerosol loading. The new mechanism is being used to evaluate radiative effects of SOA on regional to continental scales and ascertain how changes in energy-related emissions could affect SOA and its radiative effects [Chuang].

- Aerosol Process Modules for Global and Regional Applications: New biological primary organic aerosol and volatile organic carbon emission modules and improved treatments of secondary organic aerosols and cloud-activation are being tested and evaluated in the CAM and GU-WRF-Chem models [Meskhidze, Zhang, \& Kamykowski].

All of these modeling activities address ASP's mission by demonstrating improvements in the representation of aerosol processes in models that can then be transferred to global climate models. As the basic understanding of aerosol evolution is improved, the uncertainties of aerosol radiative forcing will be reduced.

In addition to new aerosol process modules being made available to the scientific community, aerosol process modules and their performance are documented in peer-reviewed journal articles.

A new means of making these aerosol process modules available to the scientific community is through web-portals. The following are a list of Internet sites where ASP models and aerosol process modules are being made available:

- http://www.aim.env.uea.ac.uk/aim/aim.php: A website where E-AIM can be used and elements of the extension of E-AIM to include organics have already been made available [Wexler \& Clegg].

- http://webmathematica.seas.harvard.edu/webMathematica/AerosolCalculator.jsp: An aerosol calculator website under development that provides a standard Internet browser interface to do sizeresolved calculations on aerosols of different chemistries. Hygroscopic growth is included as one property, and CCN activity and optical properties will be included in the near future [Martin].

- A website where the 0-D version of MOSAIC has been made available (under development) [Zaveri].

- http://www.wrf-model.org: Many of the aerosol process modules developed by PNNL (MOSAIC, aerosol optical properties, cloud-aerosol interactions) and NCSU (primary biological organic aerosol and VOC emissions, secondary organic aerosols, cloud-activation) are being distributed via the WRF community model available from NCAR [Fast, Meskhidze, Zhang, \& Kamykowski. Qian and Gustafson]. 
Alternatively, a more active involvement of ASP investigators with users of their model can facilitate the more widespread adoption of these modules. Several investigators [Ghan, Chuang, McGraw] are either directly involved in global climate modeling or have established strong collaborations with global climate modeling groups to implement aerosol process modules developed in ASP into models such as CCSM and GISS.

\subsection{Modeling Needs and Future Directions}

Current ASP modeling projects address important science issues, such as those associated with secondary organic aerosols, aerosol optical properties, and the interactions of aerosols and clouds. Other types of activities also are required to guide future research. In addition to new modeling approaches and techniques, plans for future research activities are expected to include enhancing collaborative work among ASP investigators and effectively transferring this knowledge to the global climate modeling community.

The following are possible ways to improve the modeling capabilities in ASP to advance the numerical representation of the life-cycle of aerosols and the influence of aerosols on atmospheric radiation.

\subsection{Accelerating the Use of Advanced Aerosol Property and Process Models}

Several ongoing activities employ highly complex modeling systems to study the details of aerosol formation and transformation. Examples include "master" chemical mechanisms, detailed aerosol thermodynamics, "particle-resolved" aerosol models, and "cloud-resolving" models. Such techniques are useful even if their computational expense precludes their direct use for climate predictions. In addition to providing a better fundamental understanding of aerosol processes, running these highly complex models provides a benchmark for developing reduced mechanisms and parameterizations suitable for regional or global models. Developing new parameterizations of aerosol processes based on benchmarks is not always straightforward. Consequently, additional development and testing is often needed to correctly transfer findings from benchmarks into climate models. Additional effort and enhanced organization would accelerate the transfer of new parameterizations based on benchmarks produced by ASP to the regional and global climate modeling communities.

Highly complex modeling techniques provide a fresh perspective on how to attack uncertain aerosol processes. Part of the problem with the large uncertainties in current particulate predictions may result from the fundamental framework of how particulate evolution is represented in models. For example, most aerosol models employ either an internal mixing of aerosol species or they have external mixing of a limited number of species. The recently developed particle-resolved model, which explicitly resolves aerosol evolution from external mixtures near emission sources to internal mixtures through coagulation and condensation, is more representative of reality; however, most model approaches do not account for this type of transition. New approaches, which may be computationally expensive, that can represent these processes will then be available for use in the next generation of climate models. 
These complex models (particle-resolved and master chemical mechanism) will be able to compare more directly with advanced analytical measurements employed currently by the ASP program which currently include: soft x-ray microscopy and mass spectrometry of carbonaceous aerosol and microscopic measurements of single particle mixing states.

\subsection{Improving Linkages Among ASP Activities}

The level of coordination among ASP projects (Section 2.3) can be further improved where appropriate, but it is not necessary that every modeling project should be linked closely to one another. Creating larger, integrated modeling efforts among investigators can be complicated because findings from one project need to be completed before they can be transferred to another project. Any delays or issues that arise from the first project will subsequently affect research conducted by other investigators. Thus, the success of an integrated modeling activity requires a great deal of planning to monitor schedules and progress.

There also needs to be an enhanced utilization of findings from the analysis of laboratory and field studies in ASP modeling efforts. A common practice in the aerosol modeling community is to utilize parameterizations derived from laboratory and field studies after they have published. Consequently, several years often pass between the initial development of a new parameterization and publications of a modeling study that uses the parameterization. The results can become somewhat dated as new laboratory and field study treatments develop even newer parameterizations. Another factor affecting coordination among laboratory, field, and model scientists, is that modelers have their own agenda as to what are the most important treatments to test in aerosol models. This information needs to be communicated effectively to laboratory and field scientists. The benefits of ASP's laboratory and field studies could be enhanced significantly with more active collaborations with modelers within ASP.

\subsection{Establishing Aerosol Modeling Testbeds}

The performance of new treatments for aerosol processes reported in the scientific literature is usually based on comparisons with a limited data set. Moreover, new aerosol process modules are not often compared directly with other existing treatments. While several model inter-comparison studies have been performed that quantify the differences among aerosol modules, the range of answers provides little insight on how to best improve aerosol predictions because other processes such as emissions, meteorology, and chemistry often are treated differently and contribute to the range of answers.

One consequence of the current modeling paradigm is that the performance and computational efficiency of several treatments for a specific aerosol process reported in the scientific literature cannot be assessed adequately. Occasionally there are comparisons reported in the literature, but they tend not to be comprehensive, standardized, or explore some of the extreme conditions where differences will be greatest. Reducing the uncertainties associated with aerosols in both global and regional climate models requires that the advantages and disadvantages of specific aerosol treatments be known when the meteorology, chemistry, and other aerosol processes are identical. 
A series of testbeds designed to systematically and objectively evaluate new aerosol process modules would supplement the existing approaches employed by ASP as depicted in Figure 4. Three types of testbeds could be developed: those for aerosol process and property models (including those for aerosol thermodynamics), regional models, and global models. A common modeling framework would be employed where aerosol process modules are implemented so that specific aerosol processes can be targeted using a standard test while all the other the processes are treated the same. A suite of evaluation tools will streamline the process of quantifying model performance and eliminate much of the redundant work performed among various scientists working on the same problem. Establishing reference properties for "difficult" atmospheric conditions would help modelers to focus on areas where their models and codes need improvement.

Testbeds for different types of models are needed since aerosol processes and property, regional, and global models serve different purposes. Zero-dimensional models are primarily used for constrained modeling (i.e., closure studies) and can be tested using appropriate laboratory and field measurements; however, those measurements may not be sufficient to fully explore parameter space in the 0 -D model to account for the wide range of observed atmospheric conditions. Regional and global 3-D models are appropriate for evaluating the effect and performance of a number of inputs and processes on aerosol evolution, but they contain uncertainties in all the different inputs and processes acting together. Careful design is therefore needed for all types of testbeds to ensure that improvements for the numerical treatment of aerosol processes are meaningful. To ensure that climate models produce the correct radiative forcing for the right reasons requires a good agreement between a wide range of observed and simulated meteorology, chemistry, and particulate quantities in addition to radiative forcing and having a sound foundation built upon accurate 0 -D process modules.

The testbeds would act as a means of coordinating the systematic evaluation of new aerosol process models in a single framework and help bridge the gap between knowledge gained from new laboratory and field measurements and use of this knowledge by regional and global modeling activities. The result of a series of aerosol modeling testbeds would improve how measures of performance, uncertainty, and computational efficiency are quantified over time in a manner analogous to meteorological forecast verifications made by the National Weather Service the past several decades. This information is needed by the scientific community to decide which aerosol process modules are the most appropriate climate models. 


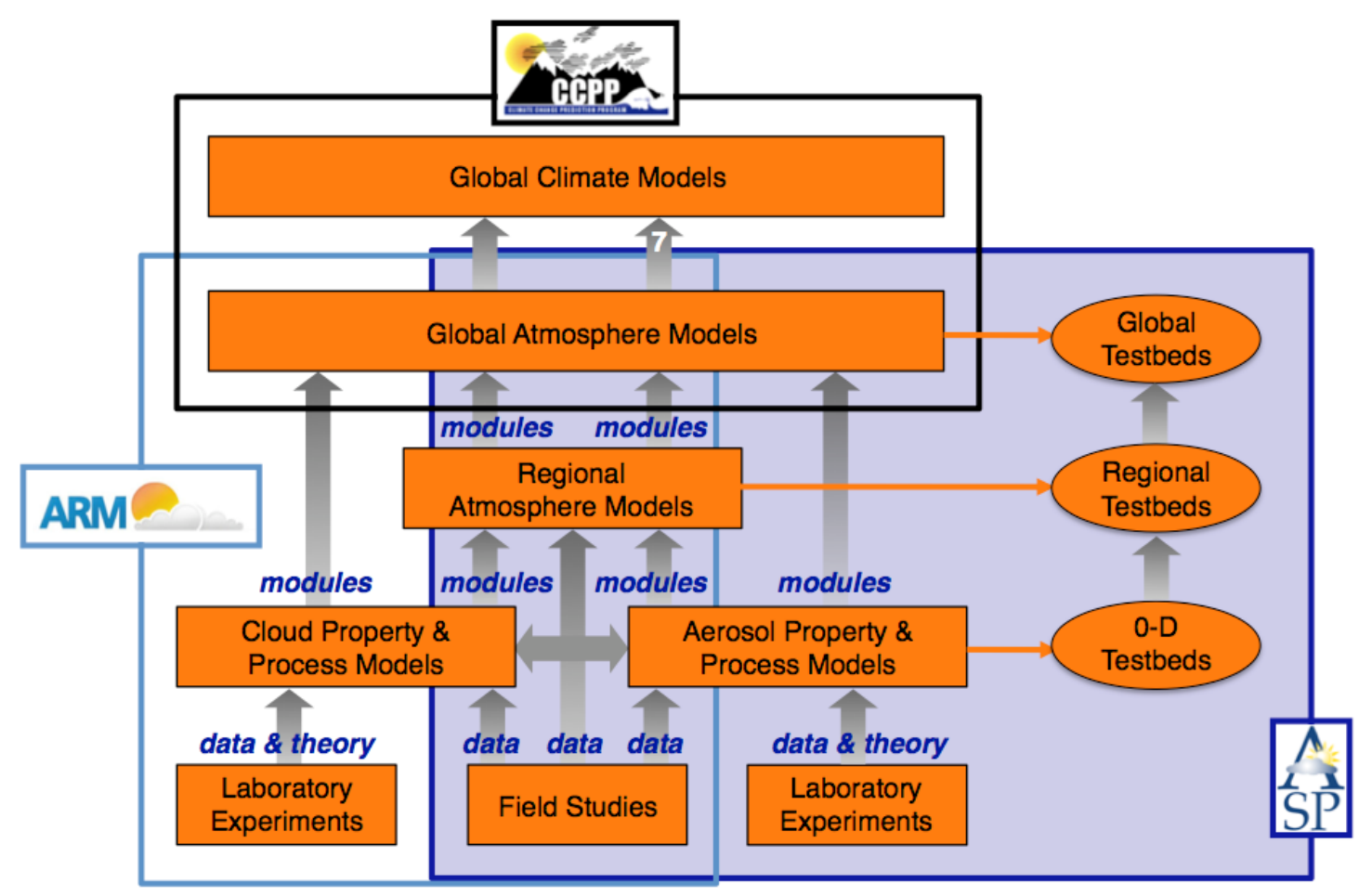

Figure 4. Relationship of Future Aerosol Modeling Testbed Future Activities, in Relation to the Fundamental Approaches Employed by ASP

\subsection{More Extensive Simulations to Better Examine Parameter Space}

Aerosol modules are exercised commonly for short simulation periods and tested against limited observational data with the result that their overall performance is not evaluated thoroughly. For aerosol property and process models, predictions may be compared with a limited number of laboratory experiments. For 3-D models, predictions are usually evaluated with field campaign observations that are collected over a few days to a few weeks. A consequence of this approach is that the performance of new aerosol process modules is biased towards the conditions observed during either the laboratory experiments or the field campaign periods and the behavior of the new aerosol process modules under a wide range of atmospheric conditions associated with climate simulations is not assessed.

Longer and more extensive simulations would fully assess the performance of aerosol modules and how they interact with other atmospheric processes under a wide range of meteorological conditions. For aerosol process \& property models, this would mean extending the simulations to include altering a wider range of model parameters. For 3-D models, this would mean employing longer simulation periods that encompass all seasons. Long-term measurements, such as those available from ARM measurement infrastructure would be used to evaluate these multi-season simulations. While the range of particulate properties obtained from long-term measurements is more limited than those available from field campaigns, the primary purpose would be to determine to what extent the new aerosol process models interact and affect other atmospheric processes. 
Performing more extensive simulations, either by examining the sensitivity of model predictions to model parameters or by performing multi-seasonal simulations, would lead to an improved understanding of the behavior of new aerosol process modules before they are implemented in climate model studies.

\subsection{Global Climate Model Link: Direct Testing}

Only a few ASP investigators are currently using global climate models; therefore, the new aerosol process modules developed under ASP are being incorporated largely into global climate models by other DOE programs and agencies. It would be useful to expand activities associated with understanding and documenting the differences between new and old techniques over global scale in terms of both accuracy and computation expense. This quantification of performance is needed to ensure that uncertainties associated with particulate predictions and aerosol radiative forcing are reduced before new aerosol process modules are used in long-term climate predictions. Being able to demonstrate the reduction in uncertainties is a fundamental part of ASP's mission.

Since DOE's SciDAC program conducts research associated with the CAM, it would beneficial for ASP to utilize this model as a means of testing and evaluating new aerosol process models. Another alternative is the WRF-Chem model, which now has the ability to run globally. ASP is already funding one project to implement new aerosol process modules within the global version of WRF-Chem. In contrast with CAM, WRF-Chem has the ability to run nested domains so that aerosol process modules can be tested over multiple spatial scales. In this way, new model formulations can be evaluated using measurements at appropriate scales compatible with the grid spacing (e.g., field campaign data at regional scales, satellite data at global scales).

As computer power continues to grow, the distinction between regional and global modeling is becoming blurred. In the not-too-distant future, climate models will be able to employ regional scale $(\sim 10 \mathrm{~km})$ grid spacing for the entire globe. However, the performance of simple treatments for aerosol processes employed by current global models will not necessarily improve when the grid spacing is reduced. There will be an increasing need to develop aerosol process modules that can be applied to multiple spatial scales that also better represent observed particulate properties.

\subsection{Summary}

While the ASP program is performing needed research associated with developing, testing, and evaluating aerosol process modules, those modeling activities can be strengthened considerably by employing one or more of the ideas described in the previous section. Improving the representation of aerosol processes in models is a challenging task that requires a greater level of effort. In this way, ASP can have a greater impact on the climate modeling community over the next decade by providing better representation of how particles evolve and affect aerosol radiative forcing. 
Appendix A

Summary of ASP Modeling Projects 


\section{Appendix A}

\section{Summary of ASP Modeling Projects}

Optical Properties of Aerosols and Optical Property Closure [James Barnard, PNNL]: The representation of aerosol properties in GCMs requires aerosol optical modules that convert aerosol chemical properties to aerosol optical properties. This conversion must be computationally efficient and accurate if these modules are to be useful. The goal of this task is twofold: 1) measurements, through field and smog chamber studies, of the optical properties of aerosols, with a particular emphasis on the wavelength dependence of the optical properties of organic aerosols, and 2) using these optical properties, ancillary chemical information, and the aerosol computational modules to determine to what extent "closure" is achieved between chemical and optical properties. The computational modules are now being tested within the WRF-Chem framework, and we expect to continue this strategy. Once tested in closure studies, the modules can be applied to larger spatial and temporal scales, extending from regional to global, to determine how well radiative forcing is predicted, and the relative role of the optical modules, emissions, chemical transformations, and transport in determining the accuracy of forcing estimates.

Representation of Cloud-Aerosol Interactions in Regional-Scale Models [Larry Berg, PNNL]: Cloudaerosol interactions play an important role in the Earth's climate through the various aerosol indirect effects (including changes to the cloud optical properties and cloud lifetimes due to the presence of aerosols), and through changes to the chemical and optical properties of the aerosols as they move through clouds. Regional-scale models, such as WRF-Chem, are an important tool for studies of the regional impacts of aerosols and climate. These models bridge a gap in terms of both the scale and complexity between global-circulation models and cloud resolving models. This project is designed to evaluate and improve the treatment of cloud-aerosol interactions in WRF-Chem, including the treatment of aerosol activation, growth, and chemical composition. Current efforts are focused on both stratiform and cumuliform boundary-layer clouds using data collected during two recent ASP field campaigns: the Cumulus Humilis Aerosol Processing Study (CHAPS), and Variability of the American Monsoon System (VAMOS) Ocean-Cloud-Atmosphere-Land Study Regional Experiment (VOCALS REx).

Global Modeling and Validation of Formation, Transformation, and Radiative Forcing of Secondary Organic Aerosols [Cathy Chuang, LLNL]: LLNL's global chemistry-aerosol model (IMPACT) is used to simulate the size-resolved concentrations and compositions of atmospheric aerosols, including secondary organic aerosols (SOAs). Our chemistry mechanism contains 156 reactions for tropospheric photochemistry, 7 reactions for sulfate chemistry, and 11 reactions for SOA formation. We validate our aerosol predictions with measurements from surface networks to identify situations where predictions and observations demonstrate significant biases in variability. We will collaborate with field scientists prior to field campaigns to recommend particular species and anticipated levels for sampling of a number of SOA. After the field campaigns, we will use our model to analyze the transport and formation of key SOAs. We are in the process to extend our previous efforts to derive aerosol optical properties of internally mixed aerosols as a function of volume fractions of particulate water and effective absorbing and non-absorbing aerosol components. We will then provide modeling simulations/sensitivity studies 
that quantify the direct and indirect radiative effects of SOAs on regional to continental and global scales as well as how these may be changed by altering energy use practices.

Modeling Studies of Cloud Processing of Organic Aerosols using Models and CHAPS Data [Barbara Ervens, $C U$ Boulder/NOAA \& Graham Feingold, NOAA]: The role of clouds as efficient reactors for the modification of chemical and physical properties of aerosol particles will be investigated. Both numerical models and data from CHAPS will be used. The foci of our work are 1) further develop a chemical aqueous-phase mechanism that describes in detail the formation of secondary organic aerosol (SOA) mass in clouds; 2) apply a parcel model for closure studies on size (mass), hygroscopic and optical properties of cloud-processed inorganic/organic aerosols using CHAPS data using trajectories derived from Large Eddy Simulations for selected CHAPS cases (Ovtchinnikov, PNNL); and 3) parameterize organic mass formation in clouds. These approaches will be implemented into a module developed at PNNL that treats aerosol transformation in fair weather cumuli for application in regional and global climate models. The work will result in a new contribution to current aerosol models that significantly underestimate SOA mass. It will show the extent to which processes in clouds may alter chemical composition and physical properties of particles.

Synthesis of Field Observations and Multi-Scale Modeling of Aerosol Evolution and Aerosol Radiative Forcing [Jerome Fast, PNNL]: A fully-coupled meteorology-chemistry-aerosol model (WRFChem) will be used to simulate the mass, size distribution, composition, physical characteristics, and optical properties of particles as well as aerosol direct and indirect forcing over urban to regional scales. Our analyses will integrate the findings of ASP field observations and modeling developments to 1) quantify uncertainties associated with predictions of anthropogenic particles as they are transported from urban sources and mixed into the regional-scale environment, 2) examine how those uncertainties affect the estimates of direct and indirect forcing, 3) determine whether urban to regional-scale variations in aerosol radiative forcing are significant in terms of global climate modeling, and 4) identify which key processes resolved by urban to regional-scale simulations need to be better represented in global climate models. A comprehensive approach that synthesizes data analysis and modeling is used to elucidate aerosol-chemistry-cloud-radiation feedback mechanisms. Measurements obtained during both past (e.g., MILAGRO) and upcoming (e.g., VOCALS) ASP field campaigns will be used. Improved aerosol parameterizations will be tested and evaluated within our modeling framework. Because WRF-Chem is a community model, improved aerosol treatments evaluated under ASP will be disseminated easily to the larger aerosol and climate scientific community.

Formation of Secondary Organic Aerosols (SOA) via Nitrate Ion Photochemistry in and on Particles [Barbara Finlayson-Pitts, UC Irvine]: The objectives of the proposed research are to investigate a new reaction mechanism for secondary organic aerosol (SOA) formation in the atmosphere, and to assess its potential contribution to global climate change through the introduction of this new chemistry into local, regional and global scale models. This mechanism involves oxidation of gases to form low-volatility products at the surface of nitrate-ion containing particles during irradiation in the actinic region, as well as the possibility of converting low-volatility products on the surface to more volatile species. Specific objectives include: 1) elucidate the importance of reactions between intermediates of nitrate photolysis and volatile organic compounds from anthropogenic and biogenic sources found at the surfaces of nitratecontaining particles in the atmosphere; 2) determine the contribution of this process to the formation of SOA- in the atmosphere; 3 ) measure changes in the physiochemical properties of nitrate-containing particles as the oxidation proceeds; 4) search for evidence of this chemistry in field samples; and 5) develop a parameterization for SOA formation via this mechanism that uses the molecular-level insights 
gleaned from the experiments for new inputs into models relevant to global climate change. The result of this research is a quantitative assessment of the contribution of particle phase nitrate ion photochemistry to the formation of secondary organic aerosol in air and their subsequent contribution to global climate change via scattering and absorption of light.

Natural Radionuclides and Isotopic Signatures for Determining Carbonaceous Aerosol Sources, Aerosol Lifetimes, and Washout Processes [Jeff Gaffney, UALR]: Tropospheric residence times of sizefractionated fine aerosols are being determined by examining the relative amounts of the attached natural radionuclides, ${ }^{210} \mathrm{~Pb},{ }^{210} \mathrm{Bi}$, and ${ }^{210} \mathrm{Po}$. ${ }^{7} \mathrm{Be}$ are being examined to evaluate upper air sources of aerosols as well as aerosol washout rates. Total ${ }^{7} \mathrm{Be}$ and ${ }^{210} \mathrm{~Pb}$ contents also can estimate the amount of aerosol originating from upper-air transport. Stable ${ }^{13} \mathrm{C} /{ }^{12} \mathrm{C}$ and ${ }^{40} \mathrm{~K}$ data and ${ }^{14} \mathrm{C}$ are obtained to evaluate biomass burning contributions to the optically absorbing aerosol. Lab studies using field samples are evaluating the aqueous stability of radionuclide tracer attachment as a function of $\mathrm{pH}$. Results of field and laboratory work allow aerosol mean residence times as a function of size, washout efficiencies of $\mathrm{BC}$ and total aerosols, and sources of $\mathrm{BC}$ and associated organic aerosols, to be estimated. This allows for direct intercomparison with model lifetime assessments as well as source contribution evaluations. This effort involves collaborative research between UALR, the University of Illinois, Chicago, and LLNL. We also are collaborating with other ASP researchers in making the carbon isotope and radionuclide data available for correlation with other measurements such as optical characterizations, and detailed fine aerosol chemical composition measurements.

Field Measurements of Atmospheric Aerosols for Organic Speciation, Mixing State and CloudAerosol Interactions [Mary Gilles, LBNL \& Alexander Laskin, PNNL]: In order to provide useful information on the complex nature of aerosol speciation, mixing state and cloud-aerosol interactions, multiple advance analytical techniques have been implemented in the field. The information provided by these techniques is essential to model development and evaluation. Computer-controlled scanning electron microscopy (CCSEM) has the ability to analyze thousands of particles to obtain size, shape, and elemental composition on elements (other than $\mathrm{C}, \mathrm{N}$, and $\mathrm{O}$ ). The scanning transmission $\mathrm{x}$-ray microscope (STXM) provides complementary information by providing spatially resolved quantitative molecular bonding information on the lighter elements, specifically, $\mathrm{C}, \mathrm{N}$, and $\mathrm{O}$. Combing both sets of information can identify how different components, as well as different types of carbon, are mixed within single aerosol particles. Such mixtures have profound effects on aerosol properties such as optical and cloudaerosol interactions. During a range of field campaigns (Max-Mex, ISDAC, MASE, and VOCALS) microscopy samples were collected to explore the carbonaceous aerosol transformation and cloud aerosol interactions. For the Max-Mex study, carbonaceous aerosol transformations were observed by analyzing samples collected progressively farther from the city on selected days. Cloud aerosol interactions will be explored for both arctic aerosols (ISDAC) and marine boundary layer particles (MASE and VOCALS). Besides microscopy measurements, newer peripheral measurements have been added to gain more insight into the ambient aerosol. For VOCALS and ISDAC, a CCN counter also was deployed to enable cloud droplet closures. For Max-Mex, filter extracts have been analyzed using electrospray ionization/high resolution mass spectrometry to provide empirical formulas for intact molecular species as a function of age.

The Explicit-Cloud Parameterized-Pollutant (ECPP) Parameterization for Multiscale Modeling Framework Models [William Gustafson Jr. \& Steve Ghan, PNNL]: Most estimates of aerosol indirect effects on the global energy balance have either completely neglected the influence of aerosol on convective clouds or treated the influence in a highly parameterized manner. Embedding cloud-resolving 
models (CRMs) within each grid cell of a global model provides a multiscale modeling framework (MMF) for treating both the influence of aerosols on convective as well as stratiform clouds and the influence of clouds on the aerosol, but treating the interactions explicitly by simulating all aerosol processes in the CRM is computationally prohibitive. An alternate approach is to use horizontal statistics (e.g., cloud mass flux, cloud fraction, and precipitation) from the CRM simulation to drive a singlecolumn parameterization of cloud effects on the aerosol and then use the aerosol profile to simulate aerosol effects on clouds within the CRM. This project is developing a parameterization based on these techniques to improve the representation of aerosols and their effects in MMF models. The WRF-Chem model is used in CRM mode as a cost-effective framework in which to develop ECPP before implementation in the full MMF model.

Characterizing Aerosol Distributions and Optical Properties using the NASA Langley Airborne High Spectral Resolution Lidar (HSRL) [Christopher Hostetler, Richard Ferrare, \& Jonathan Hair, $N A S A / L a R C]$ : The NASA Langley airborne High Spectral Resolution Lidar (HSRL) is deployed during DOE ASP field missions to remotely measure aerosol backscattering, extinction and optical thickness profiles, and to evaluate how these measurements can be used to characterize aerosol type and determine key aerosol optical properties and microphysical parameters. These measurements also are used to 1) map the vertical and horizontal distribution of aerosol type, 2) determine the relative contribution of various aerosol types to aerosol extinction and optical thickness, 3) investigate how the various optical properties measured by the HSRL vary in proximity to clouds, and 4) assess model simulations of aerosol transport and PBL growth.

Uncertainty Analysis [Rao Kotamarthi, ANL]: The central goal of our work is to address the following question: How can we quantify the uncertainty in data and models of aerosols and radiative forcing? Uncertainty in models can arise from emissions, initial condition, boundary conditions, and process parameters. Numerical methods available for addressing model uncertainty include Monte Carlo methods, Bayesian methodologies, and a combination of the two. To address this problem, over the past year we have developed several methods and tools. We developed simpler single-tracer versions of the regional chemical-transport models (CTMs) and used them to develop a procedure for model inversion that addresses emission uncertainties. We also developed an approach based on the EaKF for evaluating initial conditions and process-related uncertainties. We started working on developing uncertainty in measurements and representing data as "data ensemble." We are nearing completion of a coupled regional-scale model for evaluating aerosol processes and related uncertainties at very high spatial resolution. Parameter sweep procedures are being implemented to evaluate process parameter uncertainty on HPC machines to generate a large number of ensembles. As a result of our work we expect to develop methods for quantifying parameter uncertainty, emission uncertainties and meteorological uncertainties in estimating the distribution of aerosols in regional scale (MM5-CMAQ) and global scale models (GEOSCHEM).

Secondary Organic Aerosols: Detailed Modeling and Comparison with MILAGRO Observations [Sasha Madronich, NCAR]: Secondary organic aerosols (SOA) probably make substantial contributions to aerosol direct and indirect climate forcing, yet their origin and evolution is currently not well understood, and models severely underpredict atmospheric observations. The precursors of SOA are believed to be the extremely complex oxidation intermediates of gas phase hydrocarbon chemistry. We have developed the most detailed atmospheric organic mechanism (the NCAR/U.Paris Self-Generating Master Mechanism) that will be applied, in the proposed work, to calculating organic gas-aerosol partitioning, including calculation of aerosol properties such as mass, composition, and spectral 
absorption. The model will be evaluated using the comprehensive data set from the MILAGRO field campaign (March 2006, Mexico), and will be used collaboratively to develop simplified organic mechanisms for estimating thermodynamic properties (e.g., vapor pressures, solubility, activity coefficients) in mixed-phase (hydrophobic and hydrophilic) aerosols (e.g., with U.C./Davis AIM model), coupling to inorganic aerosol chemistry (e.g., with PNNL's MOSAIC model), and implementation in a three-dimensional regional chemistry-transport model (e.g., NCAR/NOAA/PNNL WRF-Chem).

Spectral Absorption and Scattering Properties of Atmospheric Aerosols: Field and Laboratory Studies [Nancy Marley, UALR]: The objective of this work is to determine aerosol absorption and scattering efficiencies, optical constants (i.e., absorption and scattering coefficients, complex refractive indices, and phase function), and aerosol Angstrom exponents (AE) for absorption (AEA) and scattering (AES) as a function aerosol source, chemical composition, mixing state, chemical aging, and relative humidity (RH). This objective is being accomplished by obtaining in situ measurements of fine mode aerosol absorption, scattering and total aerosol extinction as a function of wavelength, accompanied by laboratory measurements of aerosol composition and optical properties on fine mode aerosol samples collected simultaneously in the field. In addition, focused laboratory studies of the changes in aerosol optical properties as a function of aerosol composition, mixing state, atmospheric aging processes, and changes in RH will allow for further interpretation of the results observed in the field. The sources of carbonaceous aerosol species are being determined by collaboration with another ASP project (Gaffney, UALR) focused on the use of carbon isotopes $\left({ }^{14} \mathrm{C}\right.$ and $\left.{ }^{13} \mathrm{C}\right)$ as aerosol source markers. Ongoing laboratory studies of the optical properties of aerosol samples collected during the ASP Max-Mex are being completed in the UVB-Vis-NIR-IR spectral range. These field/laboratory efforts are expanding our understanding of the chemical and physical basis for the aerosol optical properties observed in this important field study. Particular attention is given to determining the variability of aerosol absorption and evaluation of key chemical species (primary and secondary) leading to this variability. These field and laboratory methods also will be applied in future planned ASP field studies focusing on the direct aerosol radiative effects under clear sky conditions. Obtaining a better understanding of the variability of atmospheric aerosol absorption and scattering as it relates to aerosol chemical properties is a major objective of this project and of the U.S. DOE ASP. These data of fine aerosol scattering and absorption are being used to help perform model validation and to develop better parameterizations of the optical properties of various sources of carbonaceous aerosols (e.g., primary, secondary, fossil/biogenic, biomass burning, etc.). This project is collaborating with other ASP field projects (PNNL, BNL, UCI, UCSD, and UALR) by collecting and sharing optical property characteristics with aerosol chemical and physical properties determined by other ASP science projects in field and laboratory studies.

Analysis of Laboratory Observations for Retrieval of Cloud Condensation Nuclei Parameters of Secondary Organic Aerosol [Scot Martin, Harvard]: Laboratory measurements from the Harvard Environmental Chamber (HEC) are used to retrieve cloud condensation nuclei $(\mathrm{CCN})$ parameters and to construct a Köhler model that accurately predicts CCN activation of secondary organic aerosol (SOA). The objective is to simplify the computationally expensive Köhler model while retaining fidelity with laboratory observations. For example, a previous finding from dark ozonolysis of $\alpha$-pinene in the HEC indicated that computations of CCN spectra can be simplified yet remain accurate, by omitting the consideration of limited solubility for mixed SOA-sulfate particles. Current and future efforts include analyses of CCN activation for both fresh and aged SOA formed from other major biogenic precursors. Results from these efforts will be used to provide simplified Köhler equations and parameters that can be incorporated within the cloud modules of climate and chemical transport models. 
Modeling the Deliquescence and Efflorescence of Small Particles [Robert McGraw \& Ernie Lewis, BNL; Mackenzie Smith, Amanda Mifflin, \& Scot Martin, Harvard]: This project is developing theory and models for the deliquescence, efflorescence, and water uptake of small particles for comparison with laboratory and field measurements. These processes are important for the aerosol direct radiative effect and for $\mathrm{CCN}$ properties. Dry particle diameters of interest range in size from several nanometers to several microns and respond to changes in relative humidity differently depending on their size and composition. Focus is presently on inorganic salts, where extensive laboratory measurements are available, but the theoretical methods under development are much more general and will be extended to organic and mixed organic-inorganic mixtures. A new criterion was developed for predicting deliquescence onset and its dependence on particle size and composition. Process models have been developed and will be used to facilitate interpretation of water uptake measurements in terms of aerosol chemical composition and size. New analysis methods have been developed and will be applied to model the complex organic and mixed particle systems representative of the atmospheric aerosol.

Modeling the Nucleation and Growth of Terrestrial Biogenic Aerosols [Robert McGraw, BNL; Renyi Zhang, Texas $A \& M$ ]: A significant fraction of cloud condensation nuclei derive from new particle formation. Molecular processes leading to the nucleation of new particles are thought to involve complex ternary interactions between biogenic organic acids, anthropogenic sulfuric acid, and water. This year, in collaboration with Renyi Zhang of Texas A\&M, we completed several studies (laboratory and theory) on the nucleation of terrestrial biogenic aerosols. A key result was determination of the molecular composition of the critical nucleus, the formation of which determines the rate of new particle formation. From this information we derived a simple parameterization for the nucleation rate suitable for use in models of atmospheric nucleation. These results will be extended to take into account the highly nonlinear feedback processes of combined nucleation and growth. Results from this study will be applied to the interpretation of field observations of both daytime (sulfuric acid limited) and night-time (qualitatively different and seemingly organic acid limited) atmospheric new particle formation events. This data, now available over a variety of atmospheric conditions, should provide an excellent testbed for evaluating new particle formation models.

Field and Laboratory Studies Aimed at Reconciling Measured and Modeled Growth Rates of Atmospheric Nanoparticles [Peter McMurry, UM]: Growth rates of freshly nucleated atmospheric nanoparticles are often 10 to 20 times greater than can be explained by the condensation of sulfuric acid vapor alone, indicating that other species also contribute to growth. Nucleation will affect climate if nucleated particles grow sufficiently to serve as cloud condensation nuclei (CCN). The likelihood that this will happen is highly sensitive to growth rate. If growth rates are too slow, then particles will be lost by coagulation with pre-existing particles before they reach CCN sizes. Thus, it is essential that models accurately reproduce growth rates if the effects of nucleation on cloud formation are to be predicted accurately. In collaboration with Jim Smith (NCAR), we are pursuing an integrated program of atmospheric observations, instrument development, and laboratory experimentation aimed at developing models for growth rates of atmospheric nanoparticles. Smith and coworkers developed the Thermal Desorption Chemical Ionization Mass Spectrometer (TDCIMS) and are using it to measure the composition of freshly nucleated particles as small as $10 \mathrm{~nm}$. These measurements, along with parallel measurements of nanoparticle physical properties, have shown that the high growth rates are due to the uptake of organic compounds, especially low molecular weight acids and amines. Currently we are carrying out laboratory studies to investigate the thermodynamic properties of such compounds, with the aim of providing data that can be incorporated in models for growth rates. 
Effect of Terrestrial and Marine Organic Aerosol on Regional and Global Climate [Nicholas Meskhidze, Yang Zhang, and Daniel Kamykowski, NCSU]: This project will develop, improve, apply, and evaluate fully-coupled climate-chemistry-aerosol-cloud-radiation models for climate predictions during the next 50 years and reduce uncertainties in estimating the impacts of organic aerosols (OA) on climate through OA-cloud condensation nuclei-climate interactions. The two community models to be developed further and improved in this project are the NCAR CAM version 4 with PNNL MIRAGE (CAM4/MIRAGE) and the NCSU's GU-WRF-Chem. The proposed model development and improvement will produce 1) a new physically based marine biogenic emission module for both primary and secondary oceanic sources of OA; 2) an improved SOA formation module that simulates isoprene SOA from both terrestrial and marine sources, SOA formation from sesquiterpenes and oxygenated terpenes, and the new particle formation involving ammonia and organics; and 3) an improved aerosol activation parameterization that accounts for the effects of OA.

High-Resolution Process-Oriented Numerical Modeling of Aerosol Processing by Clouds [Mikhail Ovtchinnikov and Richard Easter, PNNL]: Modifications of size distribution and composition of aerosol particles as they cycle through clouds are important because they alter aerosol radiative characteristics and cloud condensation nucleus and ice nucleus properties. These processes are typically unresolved, but must be accounted for, in large-scale models. We will use high-resolution process-oriented numerical modeling of aerosol processing by clouds to provide a basis for developing such parameterizations for regional and global models. The microphysics module based on a joint two-dimensional aerosol-cloud particle size distribution provides a unique opportunity to simulate size and composition dependencies of aerosol-cloud interactions simultaneously. Data from ASP field campaigns (MASE, CHAPS, and VOCALS) will be used to constrain and evaluate the microphysics module coupled with the large-eddy simulation and trajectory ensemble model frameworks.

Modeling Aerosol Processes in the DOE Atmospheric Science Program [Stephen Schwartz, BNL]: This project develops, applies, and evaluates aerosol-microphysical modules based upon a variety of designs and modeling approaches. Host gridded models to be used include the Community Multiscale Air Quality (CMAQ) Modeling System for urban-to-regional scale modeling, which is well suited for interchanging alternative modules for various processes, the Brookhaven National Laboratory (BNL) Global Chemistry Model driven by Observation-derived meteorology (GChM-O), and the NASA GISS ModelE. A key deliverable will be a new aerosol module for simulation of generally-mixed aerosols based on the quadrature method of moments. Model application and evaluation will focus on the locations and time periods of field projects conducted within the U.S. Department of Energy (DOE) Atmospheric Science Program (ASP) and rely heavily on measurements conducted in those field projects. This project also examines means of calculating aerosol optical properties from modeled size dependent composition. A further activity in this project is inverse modeling of global aerosol forcing from observed change in global mean surface temperature and climate sensitivity determined from energy balance models.

Development of Models for Secondary Organic Aerosol [John Seinfeld, CalTech]: Global and regional atmospheric chemical transport models that include aerosol processes require a module that describes the formation of secondary organic aerosol (SOA-organic aerosol material that condenses from gas-phase oxidation of organics leading to semi-volatile products). A goal of the present project is to develop a next-generation SOA model appropriate for inclusion in atmospheric chemical transport models. Because gas-phase hydrocarbon oxidation mechanisms and the complete semi-volatile product spectrum for the important parent organics are not fully known, SOA formation models must be based on laboratory data. The nature of the SOA-forcing process is that certain volatile organic compounds are 
oxidized by the $\mathrm{OH}$ radical, ozone, or the $\mathrm{NO}_{3}$ radical, leading to semi-volatile oxidation products that partition between the gas and particulate phases. The SOA model represents the rate of gas-phase oxidation, the spectrum of semi-volatile oxidation products, and their partitioning to the particle phase. Key issues include the nature and volatility distribution of the oxidation products, the extent of aerosolphase reactions that occur, and the effect of water on the partitioning process. In developing a nextgeneration SOA model, each of these issues is being addressed, constrained by extensive laboratory chamber data.

The Sub-Grid Scale Aerosol Processing and Parameterization for Large-Scale Models [Yun Qian \& William Gustafson, PNNL]: The grid cells employed by large-scale models do not generally resolve the gradients that are commonly observed for aerosol concentrations and meteorological variables. The extent to which different subgrid-scale aerosol processes contribute to uncertainty in aerosols and their radiative forcing at global climate model (GCM) scales is uncertain. This project focuses on quantifying these uncertainties and then developing a treatment to improve the gross representation of the aerosols and their radiative impacts at the coarse model scales. The approach taken is to first do extensive analysis of the sources of error using a multi-scale modeling approach based on the chemistry version of the Weather Research and Forecasting model (WRF-Chem). Nested domains with grid spacing representative of GCMs, mesoscale models, and cloud-system resolving models are used to identify how the simulated aerosol characteristics change with scale. Examples of sub-grid scale processes to be analyzed include local forcings such as topography, emission variability, and cloud characteristics. The next step is then to use the results from the uncertainty to guide the parameterization development to reduce the impact of the uncertainty within large-scale climate models. The ultimate result will be improved climate predictions through reduced uncertainty in the aerosol forcing of climate.

Closure Studies of Aerosol Cloud Condensation Nuclei Spectrum, Cloud Droplet Activation, and Droplet Growth Kinetics [Jian Wang, BNL]: This project examines aerosol cloud condensation nuclei spectra, cloud droplet activation, and droplet growth kinetics based upon both field observations and laboratory studies. The evolution of aerosol cloud-activation properties and their spatial variations also will be studied. One key deliverable will be an efficient representation of aerosol properties for improved treatments of cloud activation in large-scale models. The representation will be constrained and evaluated using both field observations and laboratory data. The representation also will include the effect of sub-grid variation of aerosol properties on cloud formation and cloud properties.

Process Models of the Equilibrium Size and State of Organic/Inorganic Aerosols for the Development of Large Scale Atmospheric Models and the Interpretation of Field Data [Tony Wexler \& Simon Clegg, UC Davis]: This project will first develop a comprehensive and flexible computer model of equilibrium gas-particle partitioning, water uptake, size, and phase state in atmospheric aerosol systems containing both inorganic and organic compounds. Second, the model will be used to derive simplified representations of organic aerosol properties suitable for interpretation of field observations and inclusion in large-scale atmospheric climate models. The thermodynamic treatment is based upon an extension of the Aerosol Inorganics Model, and will be carried out using data from laboratory experiments (measurements of organic aerosol formation from the primary natural and anthropogenic sources) and predictive methods including results of the MCM of Madronich. Working with Zaveri (PNNL), this project will use the detailed model to develop simplified, computationally efficient, organic aerosol modules for inclusion in atmospheric aerosol models. 
Continued Development and Evaluation of MOSAIC Aerosol Module Using Laboratory and Field Measurements [Rahul Zaveri, PNNL]: The current version of MOSAIC (Model for Simulating Aerosol Interactions and Chemistry) implemented in WRF-Chem includes computationally efficient treatments for aerosol thermodynamics, gas-particle mass transfer, new-particle formation, coagulation, and optical and cloud activation properties for inorganic aerosol components. This project will update the MOSAIC boxmodel and WRF-Chem/MOSAIC by incorporating new treatments for primary and secondary organic aerosols from anthropogenic, biogenic, and biomass burning sources, black carbon aging, and their optical and cloud activation properties based on laboratory data and/or benchmark treatments where applicable (e.g., E-AIM, SGMM). A mixing-state resolved sectional representation for size distribution also will be developed. Constrained-Lagrangian modeling and local closure studies will be carried out using lab/field measurements to evaluate different aerosol properties and processes. WRFChem/MOSAIC simulations will be carried out for appropriate field studies (e.g., MILAGRO 2006, CARES 2010, etc.) to evaluate the effects of the new treatments on the predicted aerosol mass, composition, size-distribution, mixing state, and optical and cloud-nucleating properties. A highly efficient reduced version of the comprehensive MOSAIC module will be developed for use in regional and global climate models. The key deliverables include well evaluated MOSAIC aerosol modules, which will be disseminated to the wider aerosol/climate modeling community via WRF-Chem, RegCM, and CAM/CCSM.

Hygroscopicity and CCN Activity of Secondary and Processed Primary Organic Aerosols [Paul Ziemann, UC Riverside]: In this project, we are investigating the relationships between the chemical composition of organic particles (as represented by carbon number and specific functional groups) and the hygroscopicity and CCN activity of SOA and POA formed from the oxidation of the major classes of anthropogenic and biogenic volatile organic compounds (VOCs) that are emitted to the atmosphere. The general experimental approach for this project will involve the use of large-volume environmental chambers to generate SOA from reactions of VOCs such as alkenes, alkanes, and aromatics with the major atmospheric oxidants: $\mathrm{OH}$ and $\mathrm{NO}_{3}$ radicals and $\mathrm{O}_{3}$. Controlled oxidation experiments also will be carried out with surrogate primary organic aerosol (POA) particles. The modeling-relevant contribution of our work is the use of our experimental results to guide the development of parameterizations relating hygroscopicity and activity as cloud condensation nuclei $(\mathrm{CCN})$ to organic composition and sources. In particular, we use the hygroscopicity parameter as a measure of aerosol water content and relate its numerical value to SOA or POA characteristics: the structure of the parent VOC of POA compound, the oxidant, and the carbon numbers and numbers and identities of functional groups present in the aerosol products. 
Appendix B

Specific Collaborative Activities Among

ASP Modeling Projects 


\section{Appendix B}

\section{Appendix B: Specific Collaborative Activities Among ASP Modeling Projects}

In view of the importance of secondary organic aerosols to the total aerosol loading that has become recognized in the past several years, a significant theme of projects that employ aerosol process and property models is improving the understanding of SOA formation and transformation processes and how to best represent these processes in models, as shown in Figure 3. Finlayson-Pitts is examining through laboratory studies potential new mechanisms of oxidation of organics at particle surfaces via nitrate ion photochemistry that may form new SOA and/or contribute to conversion of low volatility species on particles to more volatile products. This laboratory study is linked directly to field studies of newly formed particles obtained by McMurry, where organics and nitrogen compounds are very often seen together in the smallest particles in the atmosphere, and it provides insights to Zaveri and Chuang for parameterization of these new processes. The laboratory data obtained by Ziemann, Kreidenweis, and Petters will characterize the composition, in terms of functional groups and carbon number, of SOA and processed POA produced from reactions of a large variety of VOC and POA precursors and oxidants, and will relate the aerosol source and chemical characteristics to its hygroscopicity and CCN activity. This information will be made available to Wexler and Clegg in evaluating their thermodynamic model and to Madronich to constrain his trace-gas model. Ziemann, Kredenweis, and Petters also will use E-AIM to help interpret their laboratory data. Madronich is employing a highly detailed photochemical mechanism to derive and benchmark a simpler treatment for SOA precursors suitable for 3-D models, and Wexler and Clegg are developing a thermodynamic model of gas-to-particle partitioning of the semivolatile SOA product species into aerosols containing inorganic and other organic species. These two new algorithms will be implemented in the 0-D MOSAIC model by Zaveri and evaluated using laboratory data and constrained with field measurements. Fast and Zaveri will implement the updated 0 -D version of MOSAIC into the WRF-Chem model so that the new representations can be assessed using a wider range of field measurements over regional spatial scales. Kotamarthi will likely incorporate SOA process modules developed by Wexler and Clegg and Zaveri into his 1-D aerosol process model and assess their uncertainties using parameter sweep procedures. Seinfeld also is developing a next-generation SOA model appropriate for inclusion in 3-D models. Given the common research interests in gas-phase chemistry associated with SOA precursors, gas-to-particle partitioning of semi-volatile organic species, and SOA relationships based on laboratory data, it is likely that

Madronich, Seinfeld, Wexler and Clegg, and Zaveri will collaborate on many aspects of improving the treatment of SOA in models. At the largest spatial scales, Meskhidze, Zhang, and Kamykowski will develop a marine primary organic aerosol and biogenic emission modules based on laboratory experiments and improve SOA treatments and activation of organic aerosols. These new treatments will be tested in both the CAM and Global-through-Urban WRF/Chem (GU-WRF-Chem) models. The intention of evaluating the SOA treatments in the global IMPACT model by Chuang is to develop a module suitable for the CAM climate model. Chuang will also implement the aerosol microphysics of MADRID into IMPACT in collaboration with Meskhidze, Zhang, \& Kamykowski so that two SOA 
treatments can be evaluated at global scales. In this way, new treatments for SOA formation are transferred to the broader scientific community through two community models (WRF/Chem and CAM).

Other aerosol property and process modules, such as those of Barnard's optical properties and McMurry's nucleation treatments, will be implemented into the regional modeling performed by Fast. McGraw and McMurry plan to work together on the issues related to the deliquescence and efflorescence of small particles. One of Martin's students also is working with McGraw on efflorescence and deliquescence via DOE's Global Change Education Program. Characterizing lightabsorbing carbons, their mixing states, evolution of their mixing states, and changes in the presence of carbon functional groups with age by Gilles and Laskin was part of the Max-Mex portion of the MILAGRO field campaign. Correlating optical properties of biomass burn particles with their carbon bonding was collaborative with Arnott, Laskin, and Gilles and utilized measurements at the Fire Laboratory at Missoula Experiments. The speciation of organic functional groups with age using electrospray ionization/ high resolution mass spectrometry of extracts from Max-Mex filter samples involves collaboration with Marley, Gaffney, Laskin, A., Gilles, Moffet (ASP), and Laskin, J. (PNNL). The evolution of mixing states is related to the work of Zaveri on atmospheric aging of black carbon.

Several cloud process and property model projects also are linked closely. Laskin and Gilles' studies on sulfur partitioning in the Marine Boundary Layer was part of the MASE campaign and included modeling by Zaveri and additional field studies on aerosol composition during the VOCALS campaign tie into the closure studies of Wang. Ervens and Feingold will develop a new treatment for aqueous phase organic aerosols that will be implemented in a module that treats aerosol transformation in fair weather cumulus. As part of their research they will be utilizing trajectories and other findings derived from Ovtchinnikov and Easter's cloud-resolving model. Ovtchinnikov and Easter's project is aimed at developing an improved treatment of aerosol processing by clouds through cloud processes and sulfate aqueous chemistry. Together the two projects will estimate the relative importance of various processes in modifying aerosol distribution and radiative properties and result in their new parameterized representation to be tested over larger spatial scales in Berg's and/or Ghan's project. Wang will use field measurement and laboratory data to examine the aerosol cloud activation properties and their evolutions in the atmosphere, develop an efficient representation of aerosol properties (constrained and evaluated using field data), and improve the treatments of cloud activation in larger-scale modeling studies performed by Schwartz. Schwartz is examining the sensitivity of aerosol particle number concentration to formulations of new particle formation and to assumptions on the size distribution of emitted primary particles. Meskhidze, Zhang, \& Kamykowski are implementing Nenes's cloud droplet activation module for organic aerosol-cloud interactions that will be made available in CAM and GUWRF-Chem so that they can be compared with Ghan's and other aerosol activation parameterizations.

Other linkages between the projects are likely to develop over time. These linkages will become more apparent as the findings from individual projects mature and become ready to be used by other efforts. 


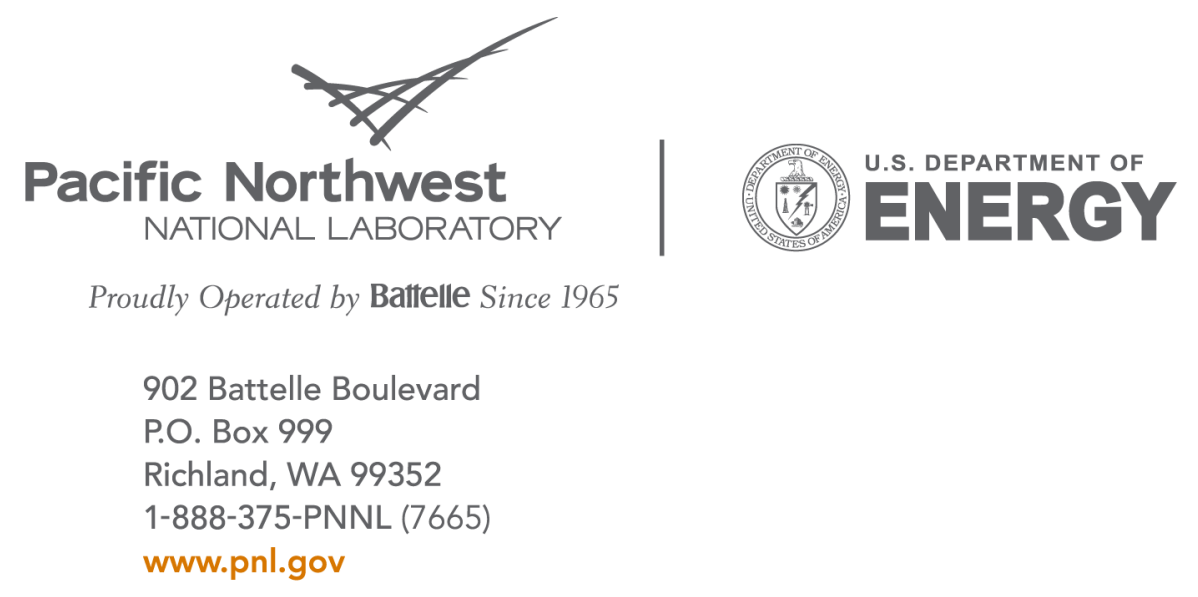

